\title{
4 \\ The Geobodies within a Geobody \\ The Visual Economy of Race Making and Indigeneity
}

In the early twentieth century, Japanese official, academic, and commercial publications deployed texts, pictures, and maps to manufacture the "large reservoir of cultural imaginaries" that have reemerged as reference points and resources for Taiwan's indigenous renaissance in the twenty-first century. In what began as a quest to wrest resources, impose administrative order, and promote immigration to an erstwhile Qing borderland in the late 1890 os and 190os, Japan's colonial administration, tourism industry, and scholarly apparatus, by the 1930s, had completed numerous projects in ethnic typification, geobody construction, and racialization to institutionalize indigeneity in Taiwan. This concluding chapter analyzes these three interrelated processes to demonstrate how the increased intensity of resource extraction in colonial Taiwan intersected with historical trends in reprographic technology and new forms of state making to ethnically pluralize the island's populations under the umbrella of an Aborigine Territory.

\section{THE GLOBAL TRANSFORMATION AS THE AGE OF ANTHROPOLOGICAL TYPIFICATION}

... [I]n premodern European discourses, non-Western peoples tend to be characterized not in any anthropologically specific terms, but as a lack or poorer form of the values of the centre. ... My analytical fiction ... [postulates] ... a shift from an absence of "the Other" (as a being accorded any singular character) to a worldview that imagines a plurality of different races or peoples. The distinctively modern and anthropological [discourse] projects natural differences among people that may be rendered at one time as different "nations," at another as distinct "races" or "cultures." The underlying epistemic operation-of partitioning the human species-makes 
possible a variety of political and ethnographic projects: particular populations may be visible as objects of government; they may serve as ethnological illustrations or subversive counter-examples in comparative social argument; and these reified characters may be available for appropriation in anti-colonialist, nationalist narratives. ${ }^{2}$

In his definition of pluralism, or anthropological typification, Nicholas Thomas argues that modern colonial epistemology "partitions" subject populations into internally cohesive, distinctive, ontologically stable groups whose unique traits are embodied in representative figures, or anthropological types. To put these modern anthropological paradigms into relief, Thomas defines premodern ethnology as its foil, in terms strikingly similar to the assessment of Qing ethnology by Japanese ethnographer Inō Kanori. For Thomas, anthropology's interest in the languages, technologies, and belief systems of remote and small populations reflects, in part, modern cultural pluralism's axiom that all peoples are inherently worthy as members of the human race. Pluralism represents an epistemic rupture from Christian and Enlightenment paradigms of incorporation/assimilation, argues Thomas. This is so because difference configured plurally has something to offer multiple constituencies, as it gains traction as the object of scientific inquiry, exotic interest, ethnic pride, or racialist pessimism. In the new dispensation, pluralism is invested with an emotional intensity that forestalls the withering away of diverse cultural formations under the impact of the homogenizing forces consolidated during the long nineteenth century's global transformation (see introduction).

For Meiji ethnologists, who defined themselves as pluralists in Thomas's sense of the word, the first Chinese travelers to Taiwan were the very picture of premodern traveler/anthropologists. They postulated an intellectual chasm between themselves and their Qing predecessors in terms not unlike the ones Thomas uses to separate premodern and modern anthropological imaginaries. For example, in 1905, a decade into Japanese colonial rule in Taiwan, Inō wrote:

When the Chinese first learned of Taiwan's location, they acknowledged the existence of the island's own people, or "the natives." ... But at the time, they only recognized the natives as a different people, with different language and customs, but did not give them a particular name. ... In Ming times, the name "Eastern Barbarians" (dongfan) was used .... After the Qing occupied Taiwan, there were two major divisions, based on the presence or absence of political compliance, the seiban and the jukuban ... They did not, [however,] make observations about race. ${ }^{3}$

As the Qing period wore on, Inō wrote, Chinese observers began to add details to their reports and make distinctions among the various non-Han peoples of Taiwan. They even propounded theories for the origins of the Taiwanese natives. But in the final analysis, the "Chinese observations about the Taiwanese natives' essential nature, in relation to race, were extremely crude. There are no theories propounded here worthy of reference in scholarly discourse. The reason for this can be attributed to one cause: they based their theories on a general view that 
recognized the natives as beyond the pale of civilization, almost as a different species, one largely excluded from humanity."

It is clear from this passage that by "race," Inō meant something more than a bundle of genetic traits that defined a Mendelian population, biologically or somatically. While Inōs project, as we shall see, essentialized and homogenized each subgroup of indigenous people through the process of typification, it also vindicated their humanity.

Thomas rightly insists that modern colonizers were far from unified in their conceptions of populations that underwent "anthropological typification." For Thomas, typification could shade into a version of relativism. Preservationist ethnologists or missionaries, in some cases, attempted to militate against the necropolitical Darwinian outlook of their fellow colonialists. In our case, Gotō Shinpei's point man on aborigine policy, Mochiji Rokusaburō, wears the black hat. In the face of their exculpatory discourse, Mochiji excoriated anthropologists for their relatively positive assessments of indigenes. In Mochiji's view, there were only two kinds of "savages": compliant and rebellious. The rebels existed beyond the bounds of sovereignty. Mochiji had little patience with pluralists and implicitly blamed them for Japan's lack of industrial progress in the uplands.

\section{MEIJI NATIONALISM AND GEOBODY CONSTRUCTION IN COLONIAL TAIWAN}

For Thomas, "colonialism's culture" locates positivities ("cultures") among the "ungoverned," "undergoverned," or "savage" peoples who are the objects of commercial, missionary, or military forces in the expanding international system. In contrast, early modern ecclesiastical/dynastic agents in such areas posited a negativity, or an absence of attributes thought to be constitutive of the imperial center, in their accounts of "barbarians/savages."' In this analysis, Taiwan's solidly colored secondary geobodies became placeholders for the positivities, or cultures, that displaced the blank, absent spaces of "savagery" in the Qing imaginary. The maps in figures 32-34 illustrate a sequence of contrasting logics.

The map in figure 32 is taken from an 1895 Japanese commercial publication; it is based on Western maps of Taiwan from the treaty-port era. In it, Taiwan is bifurcated into an eastern "savage" half and a western "Chinese" zone. The line separating the two zones is two-dimensional, stark and clear. This cartographic convention, which does not demarcate administrative boundaries or conform to natural land forms or emic senses of place but is rather a purely ideological construction, replicates the discourse on "separate Taiwans" advocated by Charles LeGendre after 1872 (see chapter 1). ${ }^{6}$ In LeGendre's view, over half of Taiwan lacked government and civility. These maps, in fact, made the argument that over half of Taiwan was terra nullius, and up for grabs in terms of international law. 

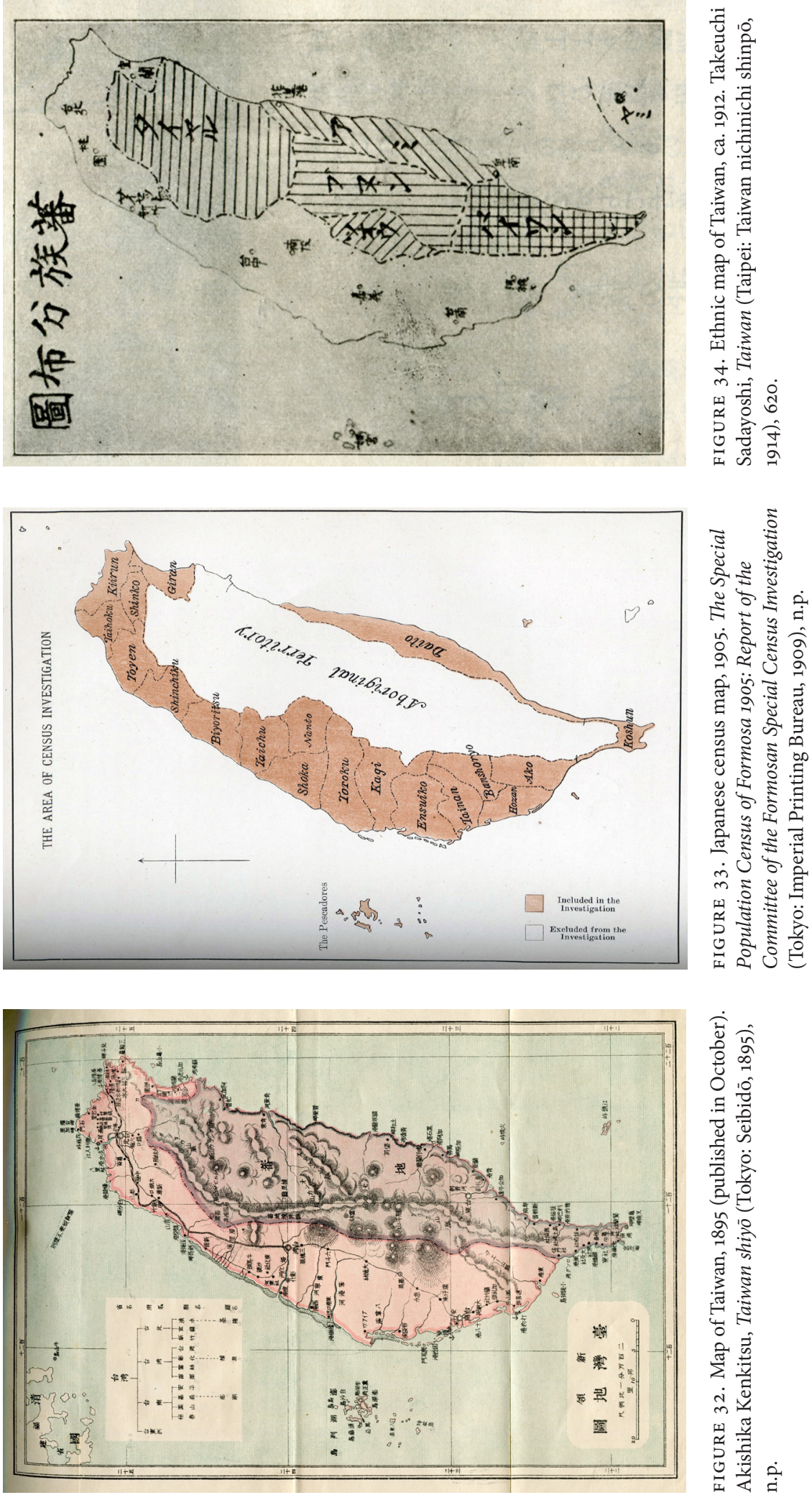
The 1905 Japanese census map (figure 33) designates the white space in its middle as the "Aboriginal Territory" This map reveals the limits of Japanese officialdom's ability to inspect, enumerate, and travel to Taiwan's interior during the camphor wars discussed in chapter 1 . The census map indicates that Japanese officialdom regarded the Aborigine Territory as a limit, beyond which it could not properly conduct the basic functions of a modern state. The third map (figure 34) filled in the blank white space of the 1905 census map with culture areas. Each shaded polygon represents a shuzoku (race/tribe) in possession of a unique language, material culture, and corpus of myths and legends. This map was paired with a photomontage of male and female ethnic types. The polygons in figure 34 are second-order geobodies in this analysis. The pictured map was published in 1914 in a commercial publication; it was based on Inō Kanori's map in figure 2, composed between 1898 and 1900.

The extension of Thongchai's geobody concept to second-order geobodies is justifiable, I think, because indigenous-territory geobodies within geobodies, like national geobodies, were strategic responses to the era's competitive imperialism. In each case, cartography was fundamentally about the mastery of space from a remote, central location at a bureaucratic apex. Whereas late nineteenth century Thai monarchs adapted an alien form of cartography to preserve autonomy in the face of an encroaching international system, the Japanese anthropologists in our story sketched their ethnic maps to extrapolate knowledge gained in limited and specific encounters to assert mastery over territories whose state of lawlessness and opacity was perceived as detrimental to the survival of the Japanese Empire. ${ }^{8}$

\section{THE GLOBAL TRANSFORMATION AS THE AGE OF RACE}

As self-aware non-Westerners, Japanese imperialists are said to have practiced a sort of mimesis as they internalized and reapplied race as a discursive weapon visà-vis other Asians, or to have refracted Western idioms in the process of becoming a full-blown colonial power. This narrative of Japanese race making as one of mimesis and/or refraction focuses our attention on the question of how race was "domesticated by the Japanese" and then redeployed in the colonies. ${ }^{9}$ As we shall see, the mimetic framework is not without value for the study of race making in colonial Taiwan. Indeed, formally trained and westward-facing ethnologists like Inō Kanori, Torii Ryūzō, and Mori Ushinosuke had a role to play in the popularization, operationalization, and conceptualization of indigenes as members of a distinct race or races. They truly exhibited the processes of mimesis and refraction, so to speak. But their formulations were mediated, modified, and contested in the mass media by metropolitan visionaries, postcard publishers, editorialist-constables, colonized subjects themselves, and myriad others who were at best loosely affiliated with explicit programs of civilization and enlightenment or Westernization. 
Moreover, the Qing precedents in aborigine administration, image production, and category construction, all of which deeply informed Japanese projects in race making, fell largely outside the history of Euro-American cultural history. In light of race's multiple and independently accreted genealogies, then, the single-origin, diffusionist model of race as subfield of European intellectual history is of limited utility for a long-term analysis of indigenous Taiwan's encounter with the global transformation. ${ }^{10}$

In light of these considerations, this chapter will adopt a looser construction of "race" as a category and social force. Following W. J. T. Mitchell, I regard race as a "medium," akin to a language game, rather than as a Euro-American pseudoscientific category that creates its own referent. Mitchell has argued that the medium of race provides the iconography and language for representing any theory, ideal, or argument that asserts the internal homogeneity and "groupness" of particular "kinds" of human beings and their distinctiveness from similarly configured groups (races). Mitchell's conceptualization recalls Thomas's definition of typification/pluralism, insofar as it minimizes the difference between "culture" and "species" as bases of invidious comparison. But it goes further. Mitchell concedes that the racial medium is often inflected with the familiar metaphor of species difference. But "race talk and race thinking" can also adopt the imagery and discourse of culture, class, status, or gender to configure difference as natural. ${ }^{11}$ Mitchell's capacious definition is salient here because, as we shall see, photographer-anthropologists, publishers, propagandists, and merchants rarely portrayed Taiwanese racial difference in strict, Linnaean terms or even in logically consistent language or iconography. Rather, race was the thread or mediating category that conjoined a mix of ethnonyms, slurs, stereotypes, and ideals into a language of difference and hierarchy.

Mitchell, along with a number of other analysts, including Patrick Wolfe, considers modern formulations of race to be the aftereffects and not the cause of racism. In other words, racism is "what hurts." Racism is the practice of discrimination, genocide, exclusion, isolation, or segregation implemented against a race. ${ }^{12}$ Qing-period (1700s-1895) resource wars along the frontier of Han settlement on the island of Taiwan produced a racism whose institutionalization provided the terminology and raw materials for Japanese race scientists to contend with in the Meiji period and beyond. ${ }^{13}$ Therefore, the use of imported Western ideas involving somatological or linguistic criteria for racial classification did not produce racism in Taiwan but did provide a new language game, or medium, for framing policy options that could exacerbate or mitigate preexisting forms of racism.

To understand the genesis, meaning, and staying power of ethnically pluralist, biologically invidious, and territorially bounded indigenous formations in Taiwan, we must not only ask what men like Gotō Shinpei hoped to achieve by institutionalizing the scientifically accredited notions of hierarchy and order imbibed during his study of medicine in Germany. We must also identify and locate the 
dispersed interests, mechanisms, and micropolitical arrangements that allowed the medium of race to proliferate and sustain itself across vast social fields. ${ }^{14}$ The power of anthropology and its related discourses is not to be found in connections between individual ethnologists and particular policies but rather in the rupture it introduced into discourse.

As the following sections will illustrate, even if few Japanese or Taiwanese read ethnological reports emanating from the highlands in the early twentieth century, ethnology reflected and inspired a plethora of lithographs, line drawings, paintings, ethnic maps, and photographs of indigenes. These artifacts circulated via newspapers, picture postcards, photo magazines, museum exhibitions, and exposition guides from the onset of colonial rule in 1895 right down to the end of the Pacific War in 1945. By the 1930s at the latest, it would have been impossible for tourists, colonial administrators, or politically conscious Japanese citizens to imagine a Taiwan shorn of its indigenous presence. Despite their relatively small numbers, about 2 percent of the island's population, the Indigenous Peoples produced by Japanese graphic artists, novelists, administrators, scholars, and the indigenes they interviewed, conducted trade with, photographed, and married covered half of the island's surface. The Atayal, Sediq, Truku, Bunun, Paiwan, Ami, Yami, Saisiyat, Rukai, and Tsou peoples were officially, academically, and popularly understood to be Taiwan's original inhabitants and were composed of several contiguous but distinct culture zones-in an interwar milieu that saw the conqueror's right to rule displaced by the discourse on sovereignty and authenticity.

The affirmation of indigenous autochthony and ethnic integrity was much more than the discovery of truths obscured by Sinocentric Qing discourse. As a broad-based repudiation of the notion that Taiwan's interior and eastern rift valley were inhabited by peoples "beyond the pale" (Thomas's "poorer version of the values at the center"), the creation of indigenous geobodies in Taiwan was, dialectically speaking, the negation of a negation. That is to say, the indigenous geobodies that coalesced in 1920 s Taiwan did not restore Indigenous Peoples to their rightful place as original owners of the island, but rather witnessed the birth of two-way symbolic traffic between a nationalized citizenry and an excluded minority that operated, for the first time, without a mediating layer of brokers such as Kondō the Barbarian, Pan Bunkiet, or Watan Yūra. This new configuration, which I have referred to as "indigenous modernity" in chapter 3, describes an international system of nation-states riddled with pockets of quasi sovereignty. This order is sustained by the persistent and even heroic efforts of indigenes to reclaim ancestral lands and maintain corporate identities in the face of detribalization and assimilation movements. As currently configured, it also requires indigenes to perform identities in ways consistent with the aspirations, fantasies, and expectations of settler/majority populations who still control most levers of state power. 
UENO SEN'ICHI AND THE PREHISTORY OF GEOBODY CONSTRUCTION IN TAIWAN

The Taiwan Government-General set up its Taipei administration in June 1895. Even before officials could safely report for duty, publications about the curious folkways of the empire's new subjects began to circulate in Japan. Especially prominent were travel accounts of hill peoples, collectively known by terms that are variations on the theme "savage," such as banjin, seibanjin, yabanjin, or banzoku. ${ }^{15}$ Takigawa Miyotarōs Shinryōchi Taiwantō (Our new territory: The island of Taiwan, published in June 1895) was typical in one respect: it recycled the report of Ministry of Foreign Affairs staffer Ueno Sen'ichi, who visited Taiwan in 1881 and $1891 .{ }^{16}$ Ueno's report, which was introduced briefly in chapter 1, is an amalgam of Ueno's firsthand observations, smatterings of cribbed material, and Ueno's translations of British Imperial Maritime Customs agent George Taylor's notes on ethnography. ${ }^{17}$ In addition to cropping up as source material for commercial publications, Ueno's notes on Taiwan were widely disseminated within Japan's military apparatus. Thus, we can assume they had been combed over by any Japanese official, soldier, or civilian with a position of responsibility in Taiwan in the post-1895 period.

Ueno began with a discussion of Qing data and classification, continued with a digest of George Taylor's observations, and concluded with his 1891 travelogue of a visit to the environs of Quchi, home of several prominent Atayal players in the construction of indigenous modernity. To orient Japanese readers, Ueno referenced the term "eighteen tribes of Langqiao." He reminded readers that this familiar sobriquet applied only to southern Taiwanese and that there were many more than eighteen tribes, even in Hengchun. According to an 1879 Qing census of the area, wrote Ueno, there were some fifty-eight villages under the jurisdiction of Hengchun, plus another forty-six villages of the "Puyuma race" (shuzoku), who also lived in Hengchun district. ${ }^{18}$

Ueno's updates supplemented a voluminous body of Japanese records from the 1874 invasion. Much had changed in Hengchun as a result of Shen Baozhen's "open the mountains, pacify the barbarians" policies of the post-1874 period. This updated baseline data was presumably useful to Japanese constables and soldiers who fanned out across Taiwan in 1895 and 1896 to set up the rudiments of rural administration. In a less practical vein, Ueno's report also provided a somewhat confused digest of existing ethnographic information. Ueno wrote that all of Taiwan's so-called shengfan (raw aborigines) could be subdivided into four ethnic groups/races (shuzoku): the Paiwan, Zhiben (Depon), Amis, and Pingpu (Pepo). This taxonomy, inherited from Taylor, left out much of the island's indigenous population and presented some logical inconsistencies. For one, Ueno subsumed the Plains-dwelling tribes (pingpu-zu) under the rubric shengfan. In contrast, later systems considered pingpu-zu to be synonymous with jukuban, a category defined antithetically to seiban. Like his crude taxonomic scheme, Ueno's descriptions of 
origin myths followed Taylor verbatim. Taylor himself relied upon oral testimony and legends to fix ancient indigenous migration routes to Taiwan, instead of having recourse to comparative linguistic data or the maps of the global distribution of cultural traits preferred by academic ethnologists of the time. For all of its problems, this shaky overview formed the baseline for Japanese ethnologists. The "four to five different tribes of shengfan discovered by European writers" mentioned in Inō’s 1895 manifesto refer to Taylor's classification, while Torii Ryūzō’s early classificatory work also cites Taylor as a pioneer. ${ }^{19}$

Ueno's report described the costume, ornaments, and physical appearance of his Atayal interlocutors but did not hazard to classify indigenes into subgroupshe instead used the Chinese term fanren (savage). As we saw in chapter 2, Ueno's report focused instead on the cultural practices that facilitated communication between Atayal people and outsiders, to serve as a practical guide for the conduct of business. Thus, the material items it assiduously described-tobacco, glass beads, red-dyed cloth, bottled spirits-were not evidence of autochthony or cultural integrity but rather were elements of a hybrid material repertoire that had sprung up between the economically interdependent but politically independent peoples on each side of Taiwan's "savage border."

\section{THE TAIWAN GOVERNMENT-GENERAL'S FIRST ENCOUNTER WITH INDIGENOUS PEOPLES}

The newly ensconced Taiwan Government-General's first official mission to Dakekan-area Atayal peoples followed Ueno's gifting and drinking playbook, some two decades later. Mori Ushinosuke classified the Atayal members of this mission as the cismontane Dakekan tribes (mae-Taikokan-ban). In the early 19oos, this group consisted of nine settlements..$^{20}$ Jiaobanshan was the largest of these.

The Japanese press and colonial bureaucracy generated at least seven written reports of the events bounded by Captain Watanabe's August 29 exploratory meeting near the Dakekan garrison and the return home of the Jiaobanshan delegation on September 12. Contemporary imagery derived from the embassy suggests that Japanese officials, writers, and publishers did not bring ethnologically informed, pluralistic categories with them to Taiwan in 1895 . These would be formulated and disseminated over the course of colonial rule, on site. For example, articulate officials like Hashiguchi Bunzō and Captain Hirano Akio employed Qing terminology for "savagery" (seiban) and mentioned specific settlements and the names of their leaders. They did not, however, use the term Atayal. Nor did they attach culture zones to ethnic maps of the island. As we shall see, the first wave of Japanese-produced icons of indigeneity in Taiwan conform to Thomas's idealtypical premodern imaginary, wherein other peoples "tend to be characterized not in any anthropologically specific terms, but as a lack or poorer form of the values of the centre." ${ }^{21}$ 
The first published Japanese illustration of an Atayal person, based on an actual face-to-face encounter, appeared in an article in the September 29, 1895, issue of the mass-circulation Tokyo Asahi shinbun. The article included a crude sketch of the woman known as Papau Iron, later known as Habairon. This line drawing made no attempt to capture individual features but was rather a schematic drawing of facial tattoos. According to this article, Habairon was about thirty-five years old in 1895; she is described as a woman bearing forehead and cheek tattoos, which signified her betrothal (probably an incorrect interpretation). The other female in the party of six Atayal who trekked beyond Dakekan and traveled all the way to Taipei with Hashiguchi Bunzō and Governor Tanaka (see chapter 1) was described as a nineteen-year-old woman named Washa Buta (Washiiga in subsequent sources). Washiiga lacked tattoos because she had married a Chinese man at the age of sixteen. In contrast to the "savages" (seiban), Chinese did not require tattooing as part of the marriage contract, according to the report. The article also specified that female cheek tattoos consisted of four bands, indicated in the small line drawing referred to above. Despite its crudity, the newspaper drawing helped to fix the female Atayal face tattoo as one of the most easily recognizable icons of indigeneity in Taiwan.

A second, more detailed sketch portrayed two participants in the Jiaobanshan encounter-an Atayal couple who did not travel all the way to Taipei-and appeared as the back-cover illustration for the 115th issue of the Journal of the Tokyo Anthropological Society (see figure 35). This sketch illustrates a short narrative description of Japanese-Atayal diplomatic exchanges in September 1895. The narrative was penned by Hirano Akio, who accompanied the September 4, 1895, Hashiguchi mission to Caoling Ridge at the foot of Jiaobanshan. Like the Tokyo Asahi illustration, there is no attempt at ethnic or racial classification in the article. The personal names "Watan Nawi, Jiaobanshan village head, and Lemoi Maton, wife of Jiaobanshan village head" are attached, under the banner of seiban no fuku (savage attire). The illustration of Hirano's note, like the cruder drawing in the Tokyo Asahi, focuses on facial tattoos as the marker of indigenous appearance, distinguishing between male and female patterns: men wore a vertical set of bars on their foreheads, while women wore the ear-to-mouth tattoos. ${ }^{22}$ The clothing, ornaments, coiffure, and headdress of the Jiaobanshan residents are labeled with great care. The detached coiffures and ornaments abstracted isolated cultural elements from individual historical actors to put Taiwanese seiban within comparative ethnography's global data set of cranial indexes, hair-strand widths, and ear shapes. At the same time, the faithfully rendered can and bottle in Lemoi Maton's backsack (see figure 11) situates the image in the shared time of frontier diplomacy, while the choice of headman Watan Nawi, who is a protagonist in the narrative account, elevates the illustration above the anonymity usually associated with "types."

These two illustrations-one mass market, the other scholarly-made gestures toward ethnographic accuracy by specifying the gender differences in tattooing 


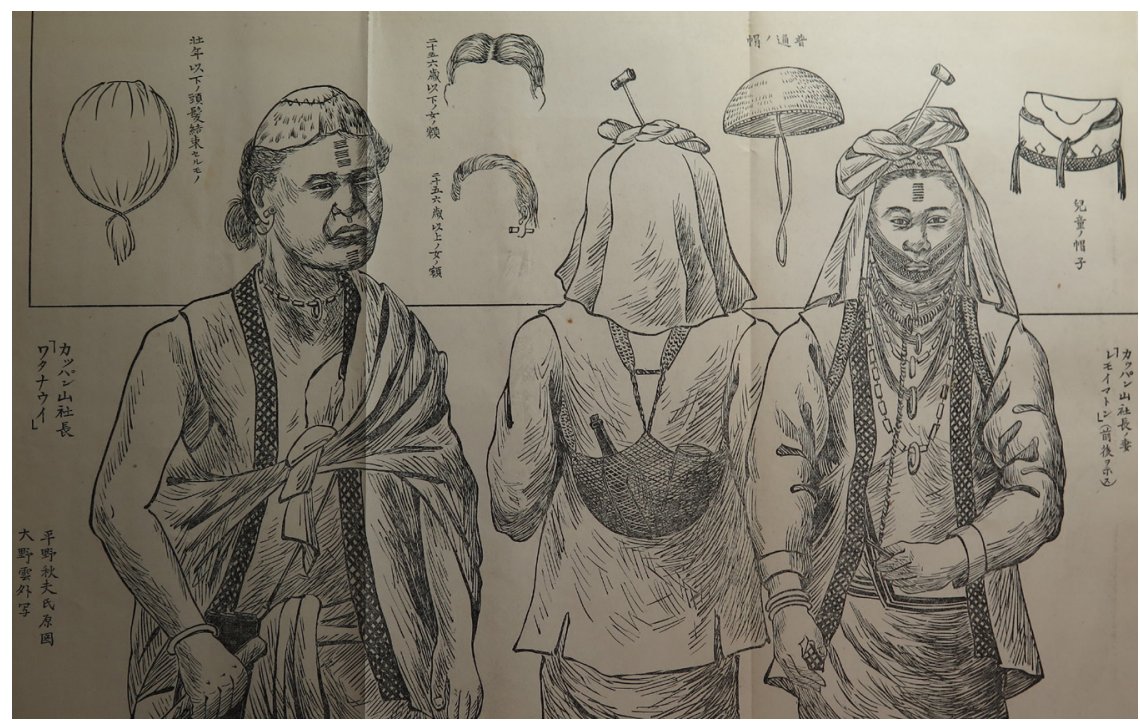

FIGURE 35. An anthropology journal sketch of Watan Nawi, 1895. Tokyo jinruigakkai zasshi 11, no. 115 (1895): back cover.

practices among so-called seiban. The next illustration, from the November 1895 issue of the general-audience magazine Füzoku gahō, overlooked such niceties (see figure 36). This drawing harked back to a venerable Japanese representational practice from the 1874 expedition.

According to the Füzoku gahō article's text (a faithful reproduction of excerpts from the official report filed by Hashiguchi Bunzō), the female indigenous interpreter Washiiga wears Chinese clothing and speaks an indigenous language, while the older woman, Habairon, was an unacculturated tattooed female in local garments. In the Füzoku gahō illustration, however, the indigenous women lack tattoos altogether, and all of them wear a combination of Atayal capes and Chinese-style blouses. ${ }^{23}$ In contrast to the ethnologically fastidious drawings in the anthropology bulletin described above, the men in the Füzoku gahō wear facial tattoos that run from mouth to ear-a patently female pattern. More than any other detail, the tattoo mix-up confirms that the Füzoku gahō artist was not working from photographs or eyewitness accounts. It is doubtful that the artist even read the text being illustrated.

Nonetheless, one element of this otherwise fanciful image did have a referent. Kabayama Sukenori, Taiwan's first governor-general, famously hosted the five Jiaobanshan emissaries and their interpreter Pu Chin in Taipei in September 1895 (see chapters 2 and 3). The inset portrait of Kabayama in figure 36 appears to be based on the commemorative photograph of the embassy. 


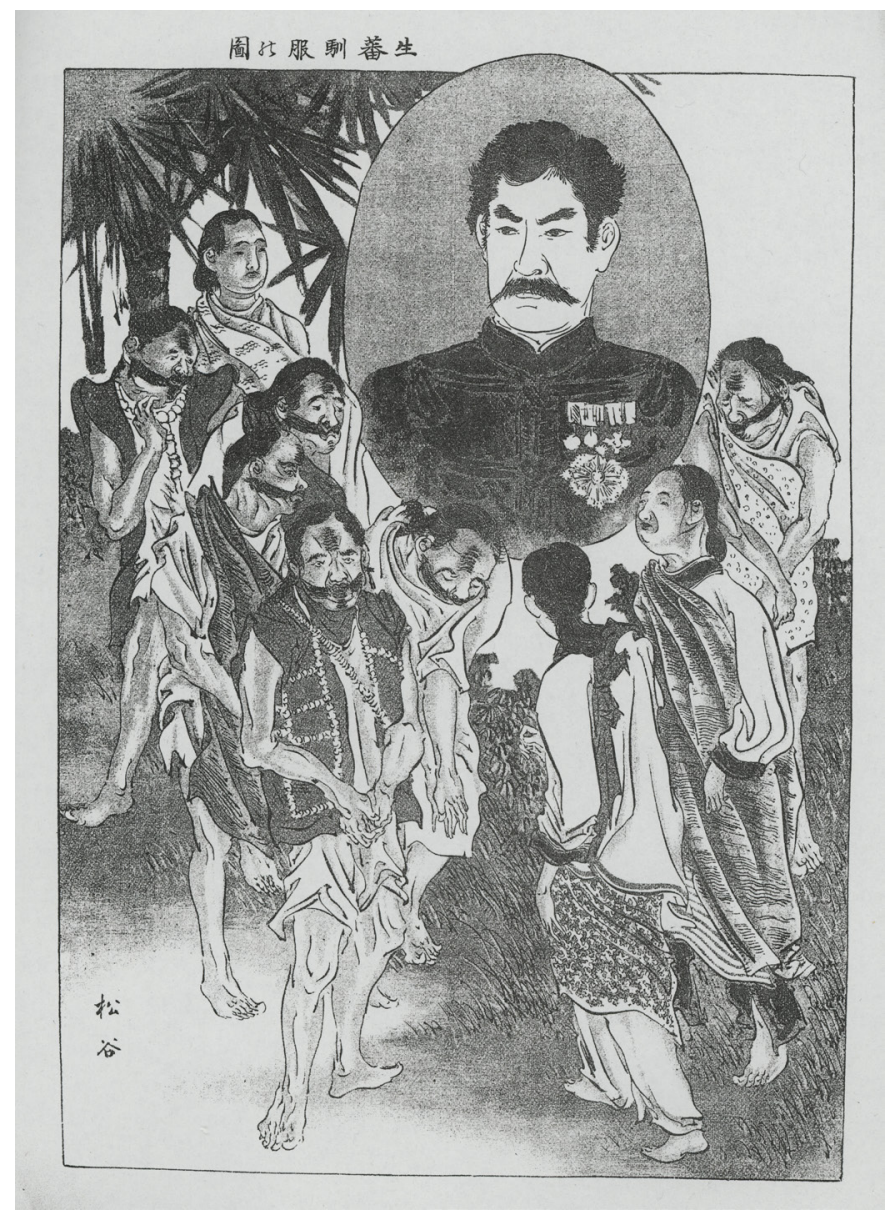

FIGURE 36. Early mass-media illustration of the Jiaobanshan emissaries and Governor-General Kabayama. "Seiban no junfuku," Fūzoku gahō 103 (November 28, 1895): 17-18.

In this version of the photograph (figure 37), one Jiaobanshan emissary stares at the ground, while another is in a crouching position-not unlike the postures represented in the Füzoku gahō illustration. The other Jiaobanshan emissaries adopt postures alien to the Füzoku gahō drawing, however. These deviations from the photograph seem purposeful. The creative repositioning of Kabayama as a smartly attired military hero, who towers over the distorted figures of supplicant indigenes, in fact echoes 1874 wood-block prints of the Japanese expedition to Langqiao. As Robert Eskildsen has pointed out, colorful wood-block illustrations of the 1874 invasion in early Meiji-period newspapers were rife with exaggerated contrasts 


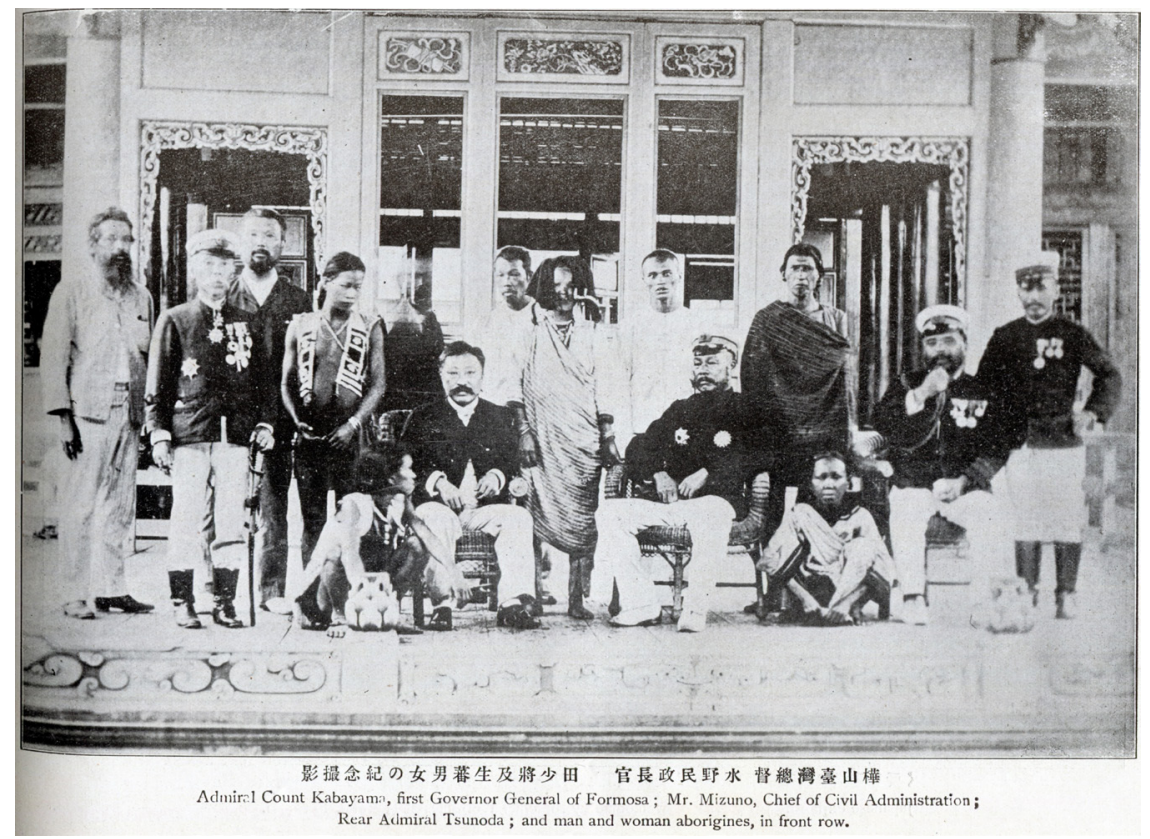

FIGURE 37. Photograph of the Jiaobanshan emissaries and Japanese officials in Taipei, 1895. Far left, an unnamed foreigner, probably the Portuguese interpreter who translated from English to Taiwanese for the Hashiguchi/Tanaka mission; 4, acting governor Tanaka Tsunatoku, who read a declaration of Japan's sovereignty to the assembled villagers near Caoling Ridge; to Tanaka's left, Hashiguchi Bunzō, who led the mission and became a key figure in early Japanese policy as governor of Taipei prefecture; next, a Jiaobanshan man named Marai (about eighteen years old); squatting below him, Ira Watan (about twenty-one years old), also from Jiaobanshan; 3, seated, Civil Affairs Minister Mizuno Jun; 2, seated, Governor-General Kabayama; standing, between Kabayama and Mizuno, Habairon (about thirty-five years old), from Shinajii; seated, to Kabayama's left, Washiiga (about nineteen years old), the Jiaobanshan woman who acted as interpreter at Caoling Ridge; standing, behind Washiiga, Motonaiban, an approximately forty-three-year-old Shinajii man; to Motonaiban's right, Pu Chin, an Atayal Chinese-language interpreter. Akiyoshi Zentarō, ed., Nihon rekishi shashinchō kinko no kan, zohō shihan hakkō (Tokyo: Tōkōen, 1914), 106.

that posed heroic and upright Japanese soldiers lording it over gaudily attired and obsequious Paiwanese people. ${ }^{24}$ By 1895 , however, the smartly dressed Japanese military man (figures 36 and 37), with medals and uniform, formed a contrast to both the crouching indigenes and the pike-wielding samurai of the 1870 .

From 1895 through 1900, embassy-related imagery was predominant in Japanese iconography of Taiwan's non-Han population. For example, one photograph of three Jiaobanshan emissaries (see figure 38) was converted into an etching for the Journal of the Tokyo Anthropological Society's January 1896 number (see figure 39). This image illustrated a text by ethnologist Inō Kanori. 


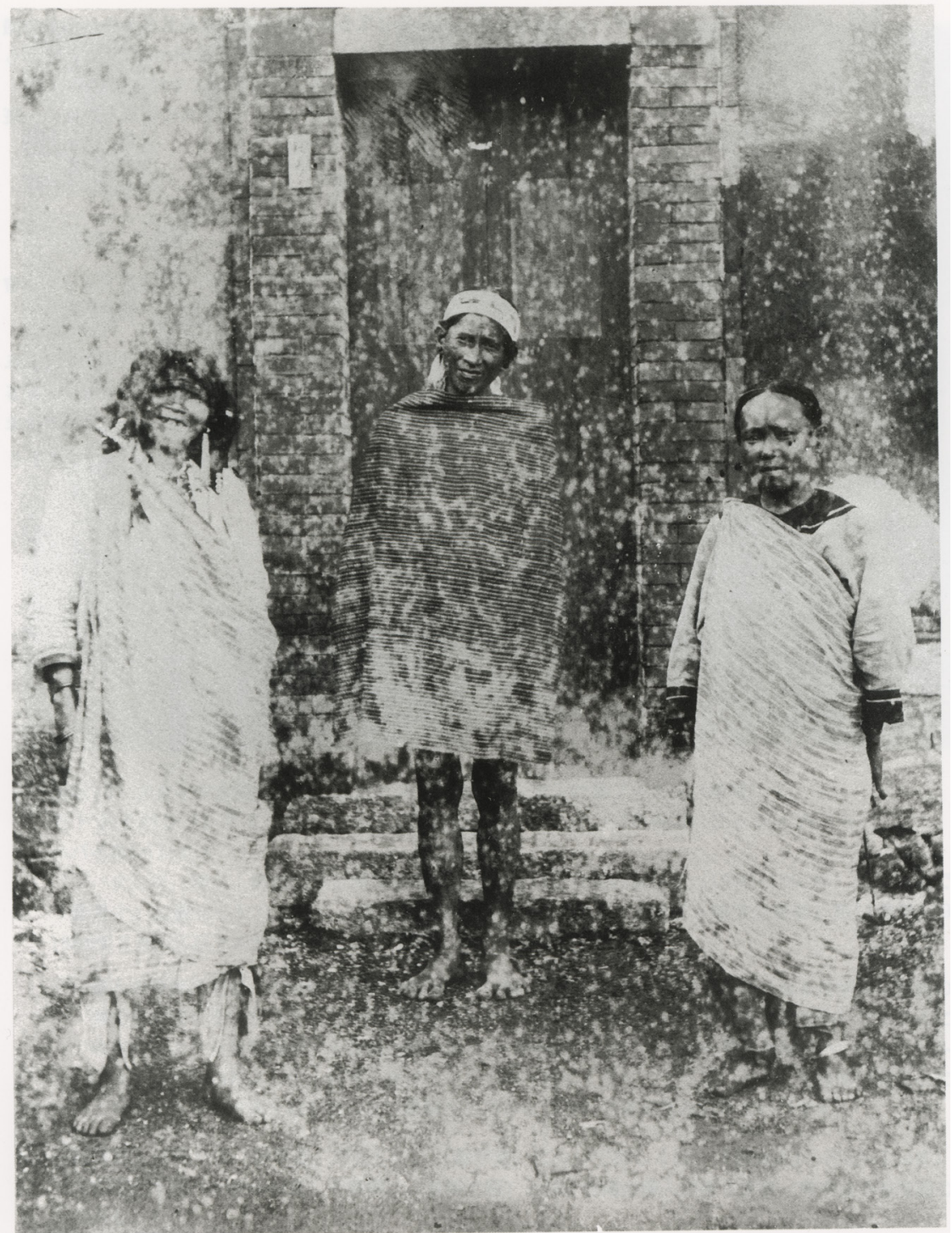

FIGURE 38. Photograph of Habairon, Motonaiban, and Washiiga, 1895. Nihon Jun'eki Taiwan Genjūmin kenkyūkai, ed., Inō Kanori shozō Taiwan Genjūmin shashinshū (Taipei: Jun’eki Taiwan Genjūmin hakubutsukan, 1999), 115. Photograph courtesy of the publisher: The Shung Ye Museum of Formosan Aborigines, Taipei. 


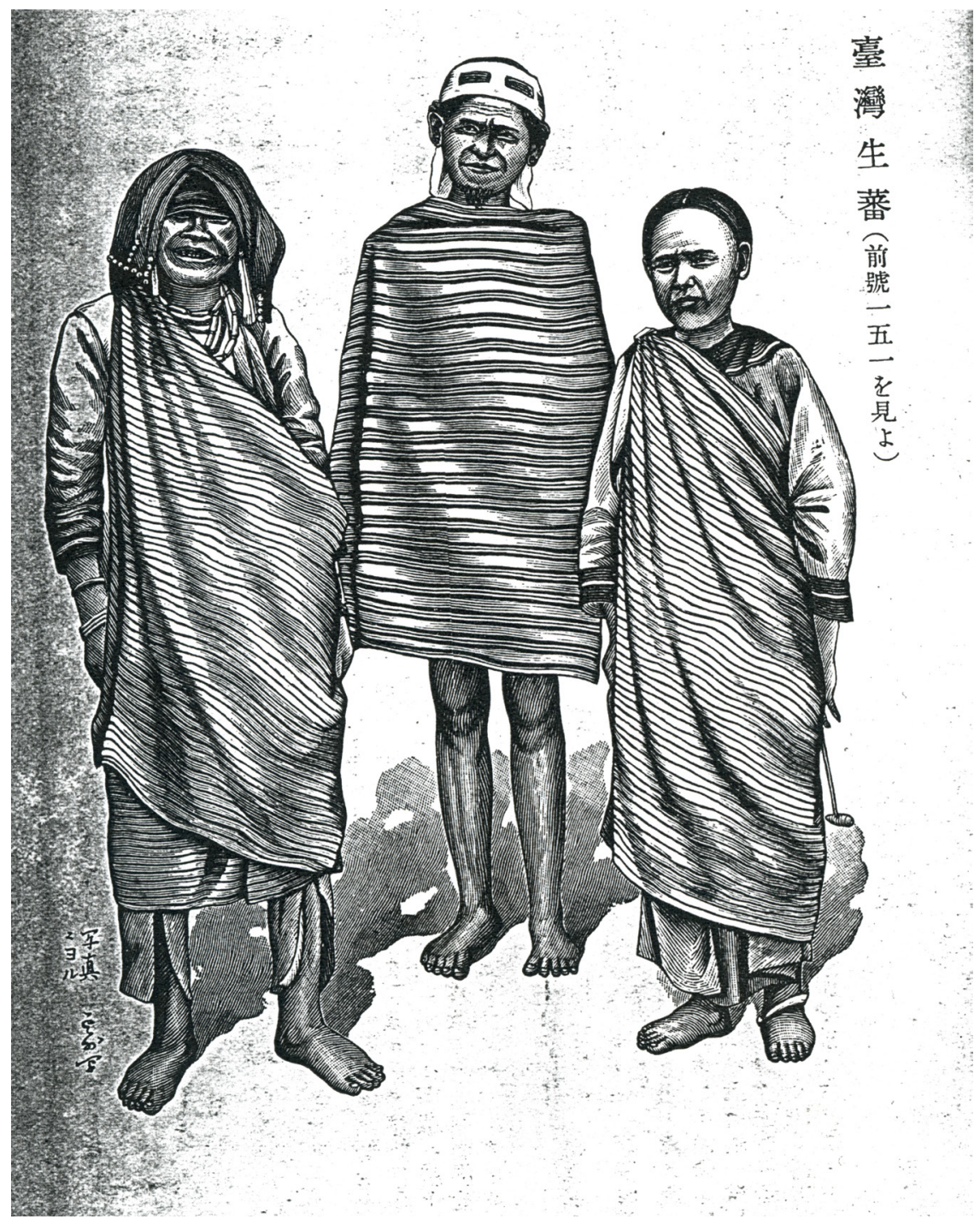

FIGURE 39. Ethnographic drawing of Habairon, Motonaiban, and Washiiga that appeared in Tokyo jinruigakkai zasshi 11, no. 119 (1896), n.p. This drawing was titled simply "Taiwanese Savages" (Taiwan seiban).

These portraits of the three emissaries Habairon, Motonaiban, and Washiiga were taken in Taipei or Dakekan walled city, to judge from the large masonry structure in the background. Whereas the Füzoku gahō illustration attempted to establish a "savage territory" setting by replacing the built environment of 
the courtyard with a bamboo grove, Inō's commissioned etching effaced the setting of the photograph completely by whiting out everything but the sitters. This form of decontextualization was a favorite tool of visual anthropologists in the Victorian era, because it facilitated global comparisons along certain narrowly defined somatic criteria. But unlike the decontextualized picture that illustrated Hirano Akio's note (figure 35), the illustration in figure 39 does not supply labels for items of material culture. Moreover, it is puzzling (in light of subsequent fabrications) that the facial tattoos described in the Tokyo Asahi article-the ethnographic marker of Atayal cultural distinction in this period-have been obscured, instead of accentuated, in this etching. Inō did, however, provide readers with a sharp illustration of Atayal textile wizardry, an element that was muted in Hirano's otherwise more detailed sketch.

The photograph in figure 40 was also staged during the Jiaobanshan embassy. It became a template for several mass-circulation images, including a photograph in a middle-school geography textbook. This portrait of Habairon, Washiiga, Marai, Ira Watan, and Motonaiban, with their interpreter $\mathrm{Pu}$ Chin, was shot in the governor-general's reception hall in Taipei. As a comparison with figure 37 indicates, the Atayal guests sat in the governor-general's and admiral's wicker chairs for a smaller group portrait, in much less stiff poses. Ira Watan (seated) and Marai were brothers (aged twenty-one and eighteen, respectively), and Motonaiban was a fortythree-year-old widower (also seated). Washiiga and $\mathrm{Pu}$ Chin are standing on each side of Marai. Habairon is seated in a wicker chair. She appears to be playing a mouth harp, which also became, like facial tattoos, a marker for Atayal femininity in Japanese iconography.

As we learned in chapter 1, newspaper and magazine accounts of the Jiaobanshan embassy attached personal names to all of the emissaries pictured in figure 40, as well as the twenty-two people who greeted Hashiguchi outside Dakekan on September 8, 1895. This textbook illustration, however, is captioned Taiwan doban, with no other supporting information. The phrase translates to "native savages of Taiwan" and utilizes idiosyncratic characters. Japanese accounts published in Taiwan always use the character ban, a carryover from the Qing period, to describe indigenes. In contrast, home-island publications used a mixed and inconsistent batch of signifiers for Taiwanese, even after standardized terminology had been fixed by the government. This 1898 textbook featured only this one photograph of Taiwanese people, making the Jiaobanshan emissaries representatives of the whole island for young readers. ${ }^{25}$

The photograph in figure 40 reappeared in an early 1900 s postcard, indicating its commercial appeal. The publishers used the more conventional term Taiwan seiban to label the emissaries. Like other pre-geobody-era publications, this one lumps the Atayal men and women from the Jiaobanshan embassy together with a Puyuma man and a group of Bunun or Tsou men (sitters in the other two photos), under the blanket category "savage." 26 


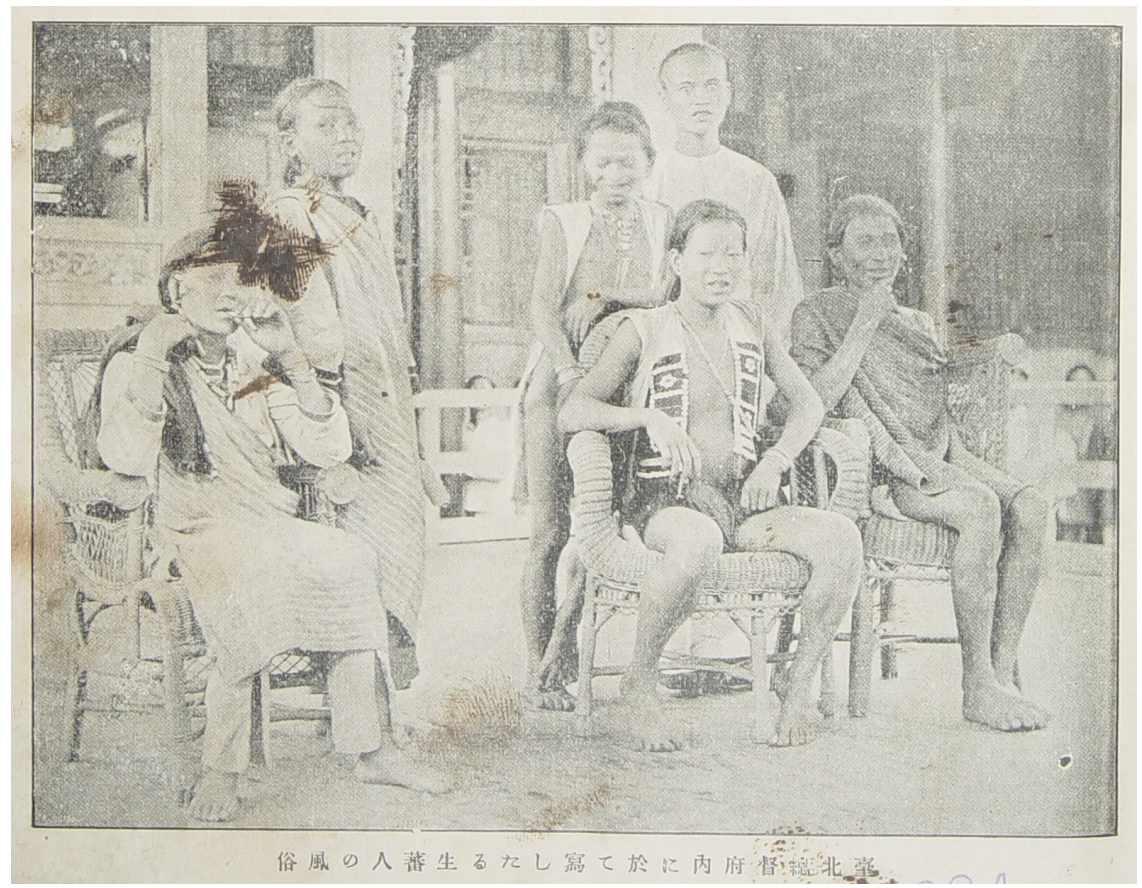

FIGURE 40. Photograph of Habairon, Motonaiban, Ira Watan, Marai, Pu Chin, and Washiiga, 1895. The photograph, captioned "Taiwan doban," was circulated in Satō Denzō, Chirigaku kyōkasho: chūtō kyōiku, Nihon chizu furoku (Tokyo: Hakubunkan, 1898), n.p. This image is reproduced from Sugiura Sosaku, Taiwan meishō fūzoku shashinchō (Osaka: Sugiura shōkō baiten, 1903), courtesy of the National Taiwan Library. Thanks to Joseph Allen for locating this image.

The 1897,1898 , and 1900 editions of Sanseidō's Teikoku chirigaku kyōkasho (Imperial geography textbook) present a radically altered version of the same photograph in a woodcut (see figure 41). Here, the artist removed Habairon's facial tattoos and mouth harp. The artist also depicted the seated Ira Watan as a standing model. The built environment, $\mathrm{Pu}$ Chin, Marai, Washiiga, and Motonaiban have been removed from the scene, probably to allow the reader a clearer view of the clothing and wicker chair that were thought to typify Taiwanese customs and manners $(f \bar{u} z o k u)$ at the time. The caption, "a picture of Taiwanese" (Taiwanjin no $z u$ ), obscures the indigenous or Atayal identity of the sitters. The Qing terms seiban (savage) and jukuban (acculturated savage) for indigenes do appear in the text but not in connection with this illustration. The Sanseidō text equated eastern Taiwan with the "savage territory", identifying it as home to the Mudan villagers who massacred Japanese victims back in $1874 .{ }^{27}$ Because the tattoos on Habairon's face are not apparent in the photograph that this etching has abstracted, it is not 


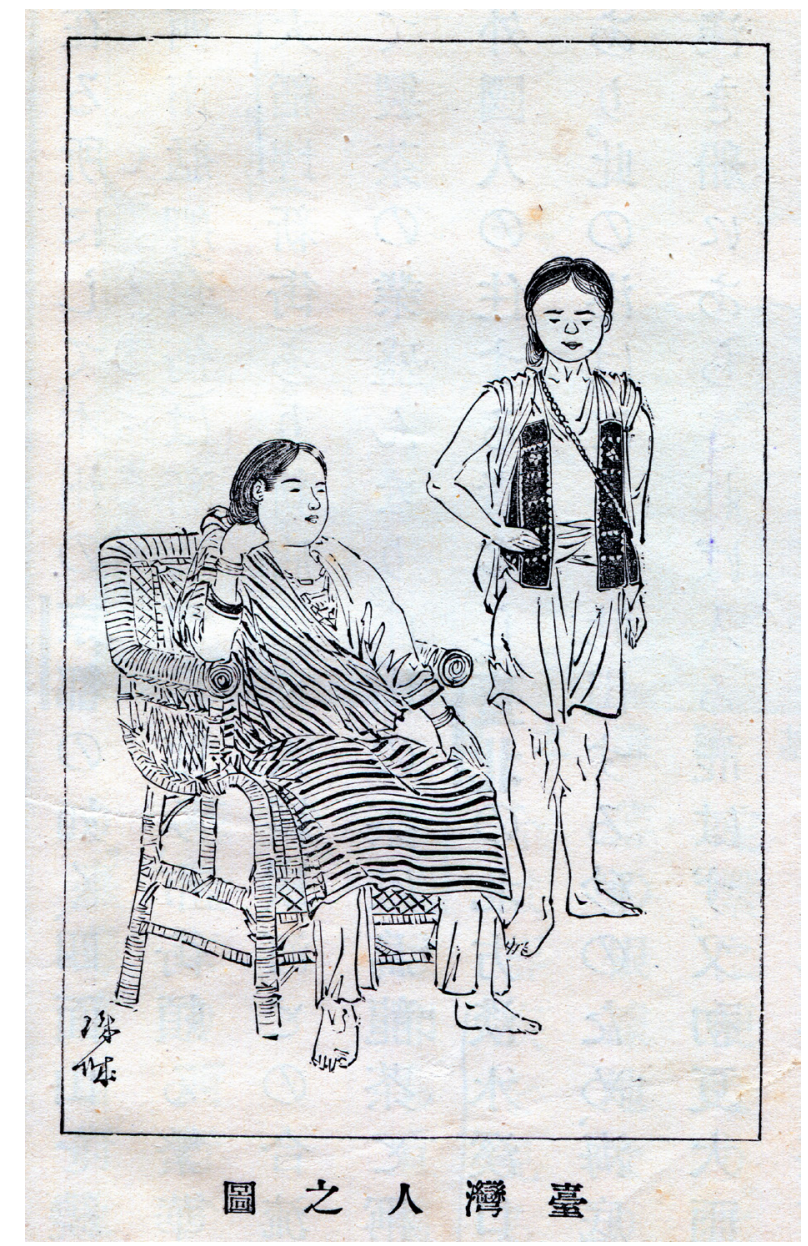

FIGURE 41. Textbook etching of Jiaobanshan emissaries, 1897. Kamei Tada'ichi, Teikoku chirigaku kyōkasho (Tokyo: Sanseidō, 1900), 152.

surprising that they were omitted. Compared to the Füzoku gahō illustration in figure 36 , this textbook etching is a faithful representation of the photograph on which it is based.

Yet another iteration of the Jiaobanshan embassy photograph was published concurrently, in 1900 (see figure 42). In this etching, the editors have retained Habairon's original hand and arm positions but have removed her mouth harp. The male Ira Watan now wears female cheek-to-chin tattoos, while the male Marai has been endowed with ponytails. Sheep, banana trees, and buildings on stilts have 


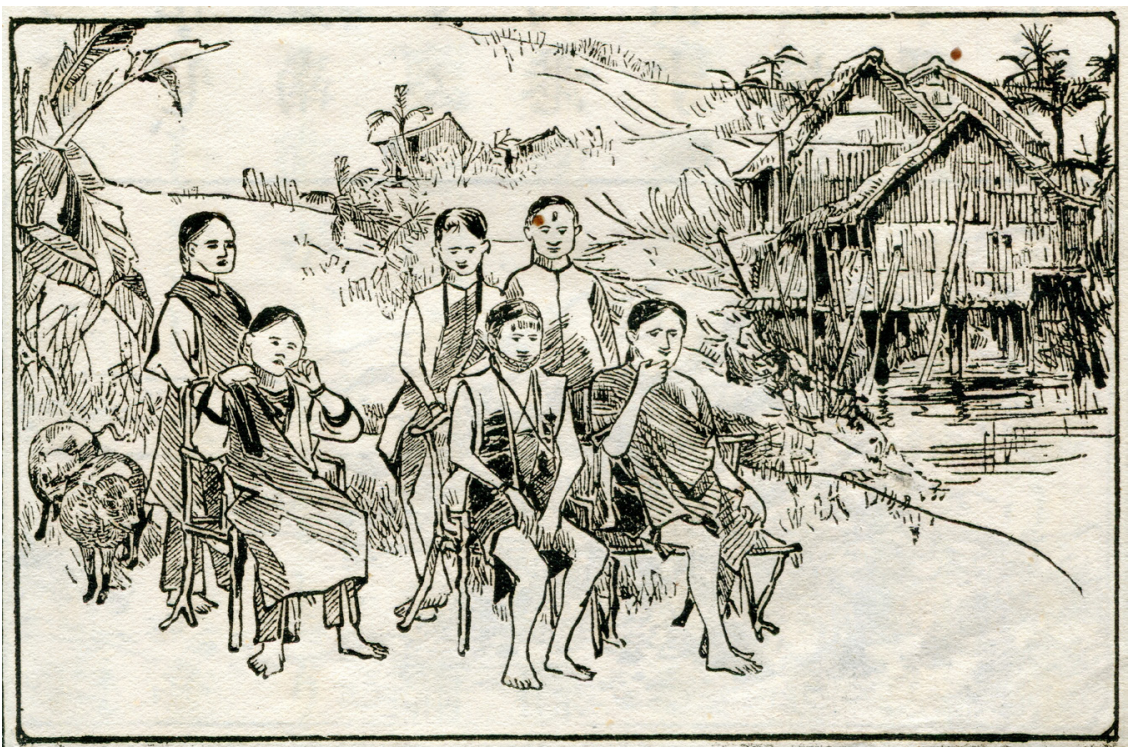

FIGURE 42. Jiaobanshan emissaries in fanciful setting, ca. 1900. Anonymous, Shōgaku chiri kansan (Tokyo: Shūeidō, 190o), 29.

replaced the courtyard of Kabayama's reception area. Presumably, the point was to place the "savages" in their native habitat, symbolized here by elevated granaries, hilly topography, tropical foliage, and domesticated livestock. Although this was an educational text, it resembles the Füzoku gahō illustration in its propensity for fabrication, enhancement, and misrepresentation. ${ }^{28}$

Two years later, an American current-events magazine called The Independent published a cropped version of the base photograph for these etchings (see figure 43). Its caption also erased the indigenous or non-Han identities of the sitters. Following the lead of their Japanese counterparts, they referred to Ira Watan, Marai, Motonaiban, and Pu Chin as generalized "Natives of Formosa." ${ }^{29}$ The only other photograph in the Independent article is of three Atayal people (see figure 18). It suggested to American readers that typical Taiwanese were adorned with little else than striped capes or beaded vests, that women wore face tattoos, and that everyone walked barefoot (see figure 18).

The preponderance of indigenes and the paucity of Han Taiwanese in Japanese textbook portraiture-as exemplified in the five editions discussed above-was given much broader extension and a state imprimatur in the first geography textbook published, in 1903, by the Japanese Ministry of Education (see figure 44). ${ }^{30}$ In its textbook, it adapted a photograph presumably taken on August 26, 1897 (see figure 45), when Inō Kanori visited Paalan-one of the major settlements near 


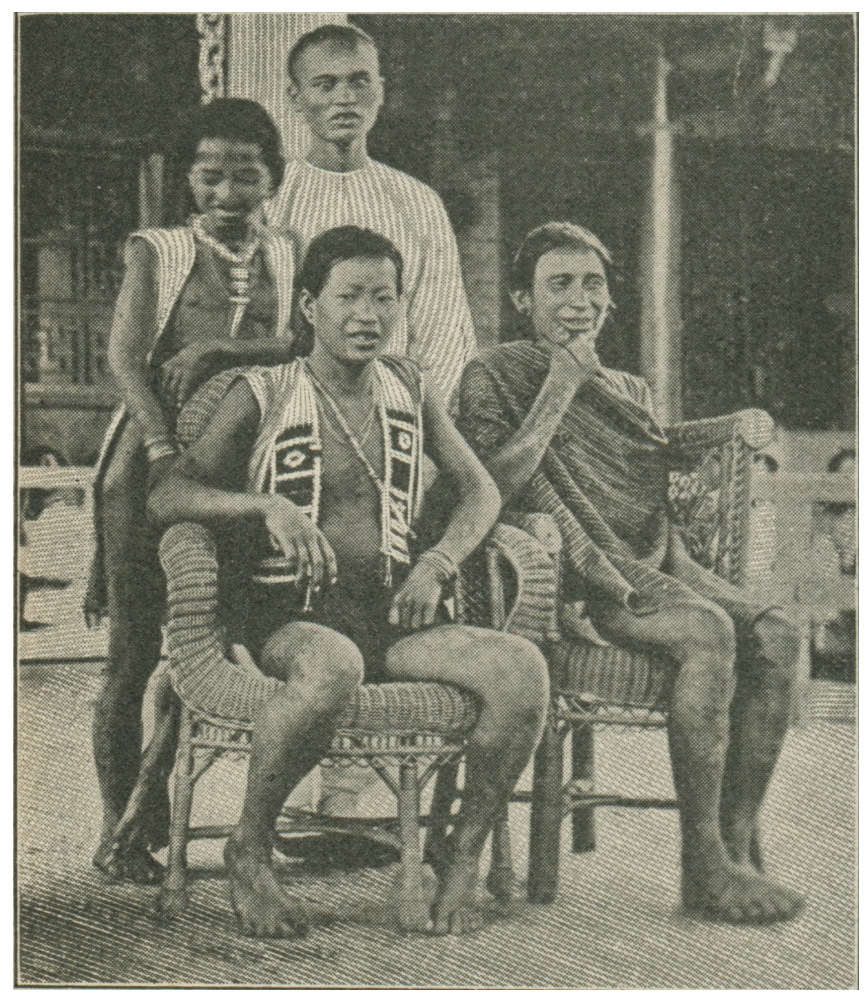

FIGURE 43. Photo of Jiaobanshan emissaries in Western press, 1902. Goto Shimpei, "Formosa Under Japanese Administration," The Independent 54, no. 2,796 (July 3, 1902): 1,582.

Wushe, and the place where Hiyama Tetsusaburō had married into a local family two years earlier. Hiyama's father-in-law, headman Pixo Sappo, is probably the man in the photograph. According to Inōs journal, Pixo gave Inō a tour, with the help of a Sediq woman named Iwan. ${ }^{31}$ This Iwan was probably Iwan Robao, Kondō Katsusaburōs wife.

As with the proliferation of Jiaobanshan embassy images, the people most accessible to Japanese official-scholars also became icons for an ethnic group (although their names have become lost to history). This photograph also appeared in Karl Theodor Stöpel's Eine Reise in das Innere der Insel Formosa und die erste Besteigung des Niitakayama (Mount Morrison) ${ }^{32}$ and as an etching in Kamei Tadaichi's Teikoku shin chiri (The empire's new geography) (see figure 46). ${ }^{33}$ A photograph of Pixo and an Atayal female with three other armed men, from the same photo shoot, was also published in the widely circulated and republished reference work by U.S. Consul James Davidson. ${ }^{34}$ 

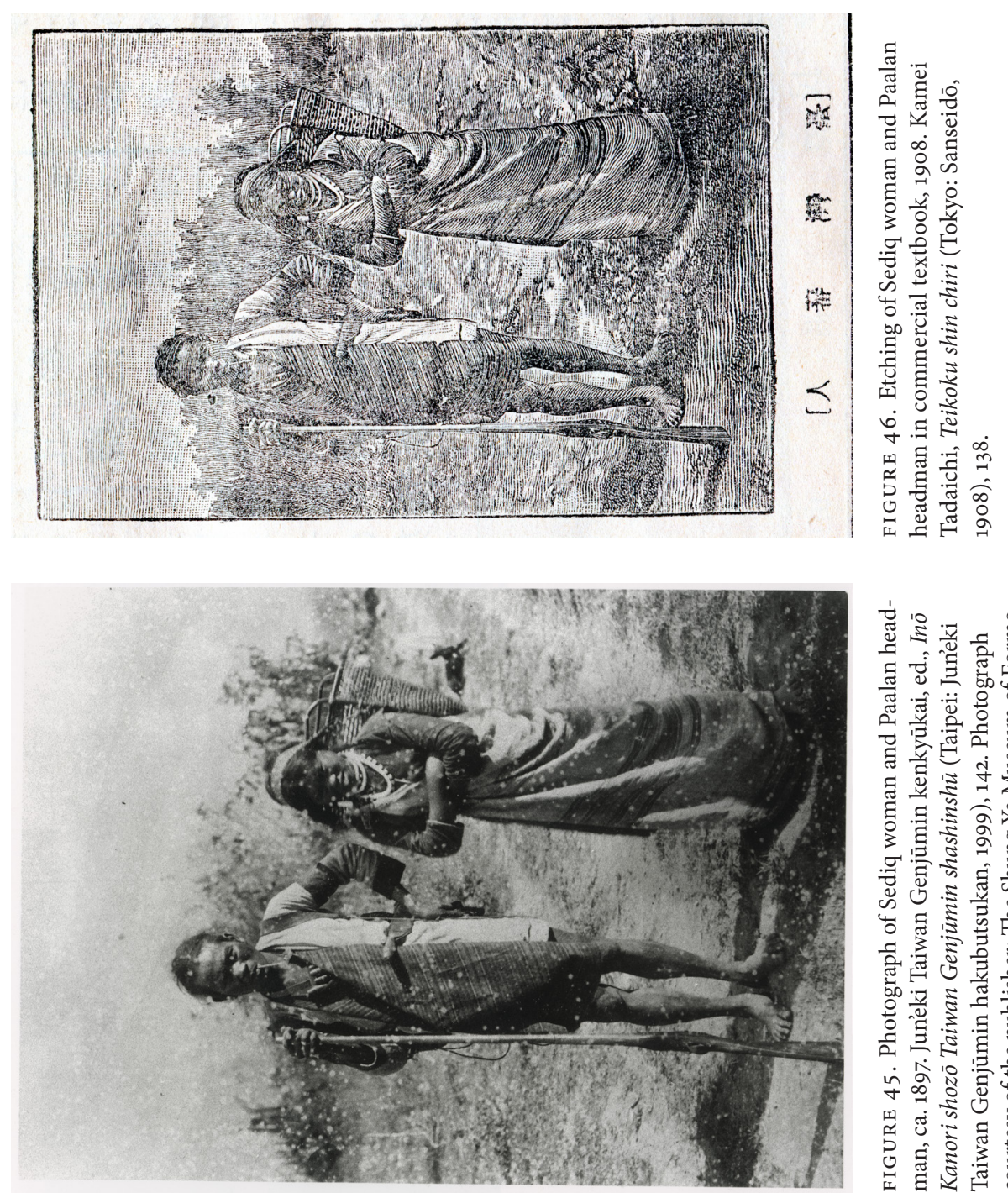

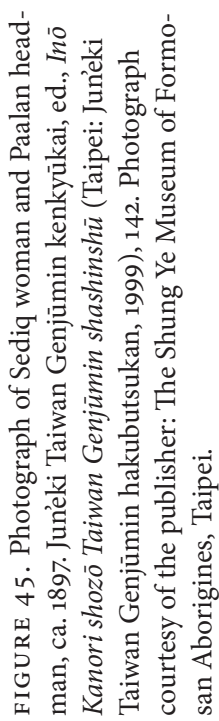
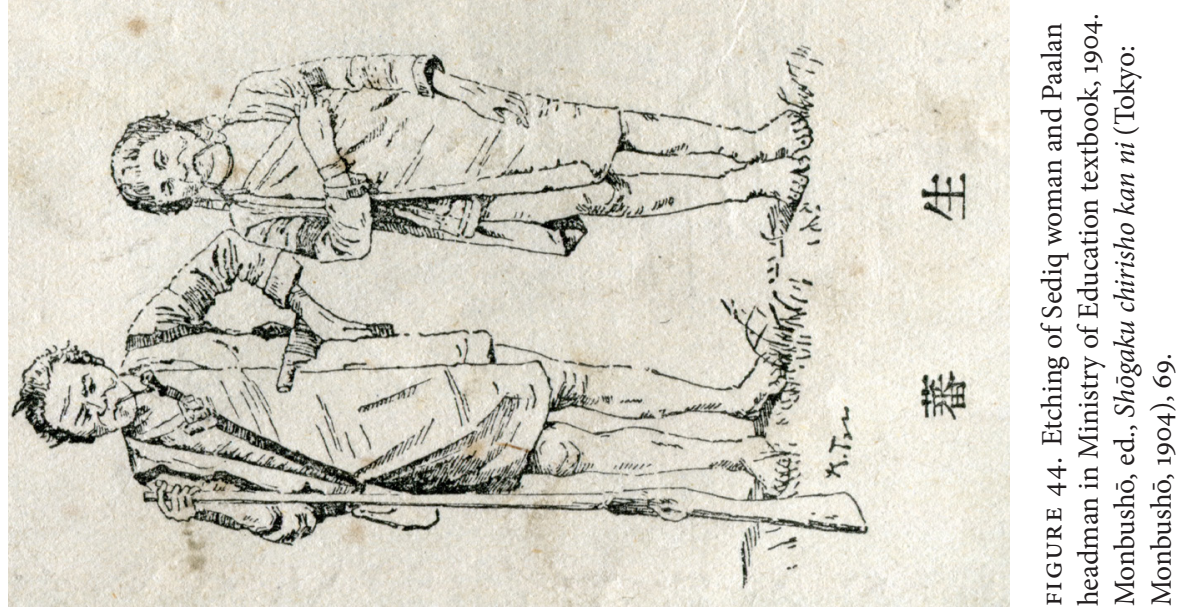
The official 1903 textbook depicts a man leaning on a rifle; he wears the trademark Atayal "savage machete" (bantō); he and the woman also smoke pipes. The female wears the striped Atayal cape so prominent in the other illustrations, but the stripes are muted in the illustration-only visible on the arm bands (figure 44). The photograph reveals the bolder stripes shown in the other illustrations (figure 45). This alteration can be attributed to the graphic simplification required to turn grayscale photographs into line drawings, perhaps. But there are notable fabrications here. First, the woman in the photograph is not smoking a pipe. And she is not bare-legged and barefoot, as in the drawing. Finally, as we saw in the etching of the Jiaobanshan photograph, her arms have been moved and her basket removed, presumably to accentuate the features of clothing and accoutrement that illustrators thought most salient. That exposed, well-defined, and fabricated bare feet were emphasized here suggests an imputation of savagery to the sitters-or perhaps the eroticization of the photo. ${ }^{35}$

The 1908 commercial textbook by Kamei (figure 46) presents readers with a more muddled etching: it is not as well defined as a line drawing, and its attempt to represent multiple shades of gray cannot be considered wholly successful. Nonetheless, it reproduces faithfully all of the elements shown in the photograph itself, with the exception of a small dog in the background. ${ }^{36}$

The portrait of Pixo and the Atayal female remained in print in official Japanese textbooks until the 1903 edition was replaced with the 1910 edition. On the one hand, the textbooks, official and commercial, deethnicized their Atayal subjects (ten years after Inōs ethnic labels had gained traction in official and scholarly circles) by invoking the Qing categories of seiban and banjin, respectively. On the other hand, the widely circulated textbook images highlighted ethnic markers of Atayalness such as striped clothing, pipes, machetes, and earrings. Even if commercial artists, education bureaucrats in Tokyo, and publishers did not know the difference between a Han Taiwanese, an Atayal person, or someone from Hengchun, the ethnographic lens that produced their base photographs put the identifying icons of Atayal ethnicity into play for a national audience.

Inō Kanori, who was at least indirectly involved in the production of the imagery described above, lodged an editorial complaint about the Ministry of Education textbook's illustration, but not because it was ethnographically suspect. Instead, Inō criticized the overrepresentation of indigenous peoples in textbooks. Not only was the majority population of Han Taiwanese given short shrift but also the textbook was "less than ideal" because it did not make distinctions among Hok-lo and Hakka Taiwanese. Moreover, he added, all seven indigenous ethnic groups should have been illustrated in the textbook. The 1903 Monbushō geography textbook also claimed that eastern Taiwan was largely wild and untamed, ignoring the large rift valley inhabited by cattle herders and farmers; Inō also took exception to this misrepresentation. ${ }^{37}$

As was the case with the Philippine Islands, where American image makers favored photographs of scantily clad Ifugao and Igorot hill peoples over suited 
and hoopskirted Filipino and Filipina urbanites, the visual rustification of Taiwan sketched above created the impression that Japan was colonizing an ungoverned territory. In the late nineteenth century, sovereignty was associated with "civilization" in the emergent international system. The painting of colonial acquisitions such as Borneo, Taiwan, or the Philippines as spaces of savagery, at this time, justified colonial occupation under the doctrine of terra nullius. Therefore, the predominance of Jiaobanshan embassy and Atayal imagery in early colonial-period Japanese publications does not necessarily attest to the emergence of a pluralist ethos in Japan, although in some respects it laid the groundwork for a pluralist sensibility by familiarizing large audiences with a visual vocabulary that could portray erstwhile savages as culture bearers.

\section{THE SCIENCE OF RACE COMES TO TAIWAN}

On November 3, 1895, the celebrated ethnologist and pioneer of Taiwan history Inō Kanori set out for Taiwan from Ujina Harbor aboard the Aikoku Maru. ${ }^{38}$ It was around this time that Inō drafted a manifesto that linked his projects in typification, geobody construction, and race science to the sound management of Japan's new colonial possession. He wrote:

The people of Taiwan are known by three types: Chinese (shinajin), cooked barbarians (jukuban), and raw barbarians (seiban). As for the Chinese, of course their descendants will become obedient citizens-it should not present much difficulty to govern them. However, the raw and cooked barbarians need to be investigated from the perspectives of natural as well as conjectural science. Thereafter, an administration and an educational policy can be structured. As for "cooked" and "raw," these are general terms formerly used to reflect degrees of submission to government. If we look at it from a scientific point of view, however, there are at least four or five different tribes/races (shuzoku) [of aborigines], as we know from looking at the articles written by foreigners who have investigated this area. But what about the intrinsic, distinctive (koyu $)$ physiologies, psychology, and local customs of the various tribes? What about their connections to the Philippine Islands and neighboring islanders? To this day, these are unsettled issues. Today, the hands of our countrymen, the clarification of these questions, will, it goes without saying, contribute to our political goals ... And we shall also obtain results in regard to our scholarly aspirations. ${ }^{39}$

From November 1895 to January 1896, with the help of Tashiro Antei, a highranking bureaucrat, botanist, and seasoned observer of Ryūkyūan customs and manners, Inō established an institutional link between the small community of Japanese anthropologists in Taiwan and Tsuboi Shogorō's Anthropological Society at Tokyo University. ${ }^{40}$ With ambitious intellectual plans but no budget, Tashiro and Inō's society would publish its correspondence and research findings in Tsuboi's Journal of the Tokyo Anthropological Society. Its anthropological specimens would be stored in Inō's Taipei dormitory. ${ }^{41}$ 
The first goal of the new organization was to establish a scholarly taxonomy of names for the different non-Han tribes of Taiwan. Inō called for scientific investigations along the following lines: biological, psychological, ethnographical, linguistic, geographic, and religious. ${ }^{42}$ In chapter 1, Kawano Shuichirō's first diplomatic mission to Yilan in November 1896 was described in some detail. One of the bicultural intermediaries, the Xitou woman named Awai, appears in Inō's first ethnological report from Taiwan. Awai acted as informant on language, village names, and local songs in the Xitou region of Yilan. Inō reproduced her testimony with his own commentary in his December 1895 digest of Tashiro's report. ${ }^{43}$ By the time Inō published his famous 1900 synthetic ethnography, Taiwan banjin jijō, complete with an ethnic map of Taiwan, he had aggregated numerous interviews with bicultural interpreters such as Awai as tabular results for use by bureaucratic higher-ups who lacked direct knowledge about local populations. At this level of abstraction, Atayal interpreters like Washiiga and Awai fell out of the picture as informants, as did the "aborigine hands" Jiku Shō Min and Kondō Katsusaburō. Like Habairon, Awai's visage was turned into a crude sketch to display her facial tattoos in Inō's article, while her role as conduit of information, trade goods, and topographical intelligence was highlighted in Kawano Shuichirōs report. We can surmise that Awai's, Iwan's, and Washiiga's prolonged association with Japanese ethnologists and policemen played a role in the ethnicization of Atayal peoples.

As Vicente Rafael has observed regarding American census categories for Philippines Islands residents, the physical process of information gathering itselfrather than the reception of written digested reports-was an exercise in identity formation for both the field-level staffers who conducted surveys and the people who provided them with information. ${ }^{44}$ Thus, it was not only anthropologists, their readers, and government officials who were buying into the new, anthropologically informed pluralist ethos. Hundreds of Taiwanese indigenes, many of them community leaders, received monetary rewards, payment in kind, or access to patronage for participating in interviews, linguistic inquiries, photo shoots, and bodily measurement exercises with Japanese survey ethnologists and census takers. They were learning, in other words, that they were Atayal, Bunun, and Paiwan peoples, instead of members of particular lineages, settlements, or ritual groups.

For Inō, the anthropologist's value-added labor was not participant observation but his global viewpoint - and ability to collate information scientifically. Referring to Lieutenant Hirano Akio's published notes, ${ }^{45}$ Inō warned readers that amateur field reports could contribute to science only after the application of his own editorial hand. Hirano described Watan Nawi's cap as made of tanuki hide. Inō pointed out that the tanuki (a Japanese raccoon dog) did not exist in Taiwan and that other reliable eyewitnesses reported that such caps were made of deerskin. Inō insisted that such details were important for ethnologists, ${ }^{46}$ who were set apart from men of practical affairs, such as Hirano, for their ability to construct evidence-based taxonomies, which would, in turn, provide a scientific foundation for colonial rule. 
In addition to interviews with indigenes or conversations with rural policemen who themselves had daily contact with mountain dwellers, Inō relied upon Qing documents, as his January 1896 report to the Journal of the Tokyo Anthropological Society reveals. In this issue, Inō referenced an unnamed Chinese record to give population estimates for Dakekan. Inō also relayed a report on methods of alcohol brewing and noted that the process might be further clarified by looking at a corroborating passage in the Danshui Prefecture "Local Customs" section of the old Taiwan gazetteers. ${ }^{47}$ In later reports, he would cite specific Qing records as evidence for a number of local practices. ${ }^{48}$

Timothy Tsu has argued that men like Inō represented a new force in Japanese Sinology. During the Tokugawa period, Japanese scholars read Chinese texts to understand the principles of statecraft, history, and family relations in order to become better human beings and governors. It was not uncommon for Chinese scholars to visit Japanese literary societies. They were lavishly wined and dined as they shared their expertise with provincial aficionados in Japan. Modern socialscientific approaches to data collection changed all of this. To govern Taiwan more efficiently, Japanese officials mined Chinese court records, land deeds, population registers, and treatises for evidence, not for theoretical insight or moral guidance. As Peter Pels put it in his discussion about a similar transition in colonized India, the colonial social scientists entered into a direct relationship with texts, individuals, and populations in order to correct the superstitious, backward, and parochial outlooks of local mandarins. Thus, Inō would be an energetic compiler, editor, and translator of Qing documents, but he remained committed to the idea that these documents supplied only the raw materials for scientific analysis, subject to his corrections. ${ }^{49}$

In the March 1896 issue of the Journal, Inō reproduced documentary evidence from the Qing archives to expose its shufan/shengfan nomenclature as anthropologically bankrupt. He documented how certain villages were classified in older Qing records as shengfan but reclassified as shufan in later gazetteers. Sometimes the two terms were used interchangeably with terms such as yefan, another word for "savage" with no particular ethnic referent. Inō also turned a critical eye to fellow countryman Ueno Sen'ichi, whose 1895 report for the Japanese army was summarized above. Inō chided Ueno for mistakenly using the toponym peipoban (plains tribe) as an ethnonym. If we recall Inōs use of the word koy $\bar{u}$ (particular) in his early declaration of "needs and opportunities" for Taiwan research, we can understand his objections. In the context of race studies as construed by Inō, koyu referred to the distinguishing characteristics of a tribe that fixed its essential nature. Terms like "unacculturated" (shengfan) and "plains tribe" described accidental characteristics shared by any number of tribes, villages, and confederations throughout the Qing empire.

To go beyond poking holes in other accounts, Inō had no choice but to follow the paths of Ueno, Hashiguchi, Kawano, and Hirano to gather information from and about peoples whose languages had yet to be recorded in dictionaries. One of his early informants, the woman who would become known to Japanese simply as Ai, 
was born around 1880 to chief (shuchō) Pira Omin of Kimunajii (near Dakekan). Meiji anthropologists prefaced much of their work in the language of hardship, solitary travel, danger, and exploration. Undoubtedly, such posturing reflected aspects of their experience. On the other hand-and quite sensibly, in a new colony among unknown tribes - these ethnologists, like the merchants and rural officials discussed in the previous chapters of this book, initially turned to the most willing and available informants. And these people tended to congregate around old Qing Pacification Offices and trading entrepôts, Dakekan being the most prominent.

Inō's informant $\mathrm{Ai}$ was seven years old when Governor Liu Mingchuan's Pacification Office was established in Dakekan in 1886. A Christian missionary named Chen Cunxin arrived circa 1890. Chen soon adopted Ai, which explains her facility in the Minnan dialect of Chinese by the time Inō showed up. As we have seen, such adoptions were common enough along the savage border, with the aim of each side to gain access to important suppliers, protectors, and patrons from across the border. Inō Kanori paid Chen and Ai a visit in January 1896. He took $\mathrm{Ai}$ on as a Japanese-language student while in turn interviewing her about her childhood in Kimunajii and taking rudimentary lessons in the Dakekan variant of Atayalic. This relationship continued for over a year, until Ai's tragic death on March 19, 1897, from a fever. According to Inō, Ai was making rapid progress in Japanese before she passed away. In his memorial article in the Journal of the Tokyo Anthropological Society, Inō characterized Ai as a shining example of Atayal people's "potential for civilization." He also acknowledged his debt to her as a native informant on language, history, and customs. ${ }^{50}$ So, before Inō barely had time to situate himself in the new colony, he had already relied upon the services of several bicultural Atayal women, including Iwan, Awai, and Ai, to make a beginning on filling in the blank ethnological spaces on the old Qing map.

Although Inō considered himself to be a race scientist, his narrowly anthropometric investigations were peripheral to his taxonomic project. In contrast to the grim, serious, and consequential anthropometry used by United States anthropologists to lend academic legitimacy to the "one-drop rule" or to "blood-quantum" politics, ${ }^{51}$ Inō's quantitative forays are incidental to his larger body of work or even to individual reports. For example, to determine Ai's racial status, Inō drew up a list of body parts and compared Ai's features to those of the "typical Japanese girl." Inōs method here was a far cry from Mori Ushinosuke's subsequent use of standardized forms, based on the famous British Ethnological Society Notes and Queries forms. ${ }^{52}$ The major headings on Inō's list were even inconsistent across studies. In Ai's case, he listed skin color, bodily hair and coiffure, eye shape, and "other parts of the face" as important constituents of racial identification. For each feature, Inō used a Japanese woman as the proxy for Asian and marked "similar" or "not" (if "not," he explained how a feature was different). Under the column bodily hair, Inō marked "similar," but under mouth, he wrote that Ai's was "comparatively bigger." For all of his efforts, however, Inō believed this method of racial classification was inconclusive. For one, 
Inōs sample was much too small. But even if this problem were ignored, Inō wrote, some of Ai's physical features were Asian, while others were Malayan, so there was no way to decide her racial affiliation based on his anthropometric investigations. In the end, Inō believed linguistic evidence was more definitive, because Ai's spoken bango (Atayal) had the flat tone (compared to the rising and falling tones of Chinese) and harsh consonants characteristic of Malay languages. ${ }^{53}$

Inō freely mixed cultural and somatic criteria in this case to arrive at a foregone conclusion: Ai was not Chinese or Japanese but was instead a member of the Malay race. This determination linked her ethnographically to the peoples of the Philippine Islands and the Malay Peninsula, while extracting her from the frontier political economy of Dakekan. In the years to come, Inō would labor to represent the "pure Malay" indigene graphically-an immense project to which we will return below. In a subsequent report based on a larger sample, Inō conducted anthropometric studies of the inhabitants of Wulai. Almost as if to invite the criticism of later scholars, Inō adopted different categories for measurement for his Wulai subjects than the ones he used for Ai, rendering a scientific comparison impossible. Inō had twenty-seven Wulai residents to work with, which led him to state that his statistical sample was too small to be meaningful. ${ }^{54}$

On the other hand, this March 1896 series of interviews, which took place in Taipei, changed the course of Japanese representational practices vis-à-vis indigenes forever and has cast a long shadow on current practices in self-representation. It was in Taipei that Inō determined that his Wulai informants were similar enough in dress, ornament, language, and comportment to his Dakekan informants to be classified as coethnics under the rubric Atayal.

\section{WULAI, QUCHI, AND THE ATAYALIZATION OF THE NORTHERN TRIBES}

Inōs March 1896 interviews with Wulai residents not only provided him with important clues for the classification of Taiwanese ethnic groups but also set the stage for the production of photographs by activating networks of ethnologists, military men, camphor capitalists, and headmen from the settlements along the Xindian River.

Inō Kanori's travel notes from 1897 and his 1900 ethnological report list Jiku Shō Min as his local informant for Quchi. Jiku came to Taiwan with the Imperial Guard in 1895. In 1896, under orders from first governor-general Kabayama Sukenori, Jiku made his way to Quchi to "pacify the locals."55 Subsequently, he married into a leading Quchi family to establish a beachhead for Japanese logging concerns in conjunction with camphor entrepreneur Dogura Ryūjirō. As an adopted outsider, Jiku took the title Watan Karaho to reckon himself a true local chief (tōmoku).56 Because Inō referred to Jiku in his famous 1900 compendium as his guide to Quchi, we can surmise that Jiku himself facilitated the March 1896 exchanges between Inō Kanori and the Wulai contingent in Taipei recounted above. 
A little over a year after the interviews with the twenty-seven Wulai residents in Taipei, Inō and Awano Dennojō formed an expedition crew to begin a 192-day ethnographic survey tour of Taiwan by order of the Bureau of Education. They began by recruiting two Han Taiwanese aborigine-language interpreters, named Kōan and Aki, both inhabitants of the interior for over twenty years. Both were married to indigenous women. Inō could hardly distinguish Aki from an Atayal man; he lacked a queue, wore Atayal clothing, wielded a machete, and traveled barefoot. Inō's party also hired Awai, presumably for interpreting, along with her two children, in the village of Rahao..$^{57}$ This Awai may have been the same interpreter who acted as Tashiro Antei's informant in the fall of 1895 .

Jiku Shō Min organized the purchase of gifts and supplies, as well as the hiring of interpreters. When the party reached Wulai, just south of Taipei, Inō and Awano were welcomed by a young bantei (brave) named Watosinai, whom Inō had met previously (probably in Taipei).$^{5}$ Watan Yūra, whose name shows up in the manuscript records of Japanese rural administration as a representative of Wulai and in Inō's list of informants from the March 1896 interviews, was also present. Inō did not return to Wulai/Quchi after the May 1897 meeting, but Mori Ushinosuke, again under the aegis of Jiku Shō Min, rekindled these ethnologist-informant relationships in 1902..

Inō's island-wide survey concluded in December 1897. At this time, we should recall, etchings based on photographs of the Jiaobanshan embassy and a few actual photographs had been circulating in Taiwan and Japan as the most widely distributed illustrations of the island's peoples. On April 23, 1898, Inō Kanori made his first major intervention to controvert these ethnologically vague and, in his view, irresponsible portrayals. Shifting the ground toward a pluralist model, Inō unveiled his newly devised taxonomy of Taiwan Indigenous Peoples with a photographic montage composed of representative "types" at an exposition in Danshui. ${ }^{59}$ On August 16, 1898, Inō's montage appeared on the cover of the first issue of Banjō kenkyükaishi (Journal of the society for research on aborigine conditions). ${ }^{60}$ The same montage was reproduced for a general readership on August 5, 1899, in Taiwan meisho shashinchō (A photo album of Taiwan's famous sites) ${ }^{61}$

Inō's montage, prefiguring the map he would publish in 1900, depicted Taiwan's ethnic groups as commensurate units, suggesting ontological parity for each. Unlike the map, however, the montage could not provide visual consistency across ethnic groups. Some of the photos are studio portraits, others were shot in situ. Some displayed noted cultural markers, others did little to distinguish their subjects from other Taiwanese. For example, the "tattooed face savage/Atayal" exemplar wears no jewelry, has no visible tattoos, and is carrying an imported weapon. This man, who hailed from Quchi, was probably familiar to Inō. In the montage, he is referred to as the "tattooed face savage" (keimenban), ${ }^{62}$ which is also glossed in furigana as Atayal.

The new ethnonym Atayal redefined the "savages" in terms of unique attributes manifested in language and material culture, neither connected to nor dependent 
upon their relationship to a Japanese or Qing imperial center. In other words, the ethnonym Atayal asserted a presence. But in asserting an ethnic presence, Inō also effaced the individual's identity. In contrast with the Jiaobanshan embassy sitters, whose names are easy to discover, clues regarding the identity of the man known simply as "tattooed face savage" remain fugitive.

A glass plate of Inō's "tattooed face savage" is held at the U.S. Library of Congress as part of the Bain News Service photographs, ${ }^{63}$ along with a portrait of two wellarmed "chiefs," two photographs of headhunters with fresh heads, and a picture of a skull shelf. ${ }^{64}$ The Bain negative is captioned "typical fighting man of the headhunters, Formosa."

The Japanese word for "savage" is also burned into the plate. The other chiefs in the Bain News Service collection are also referred to as savages, while the other three Bain negatives provide graphic evidence of seiban barbarity by displaying severed heads or skulls. ${ }^{65}$ The term Atayal is not attached to any of these photos. Other pictures of the armed man from Inō's 1898 montage have been reproduced in the 1999 book Kanori shozō Taiwan Genjūmin shashinshū (Images of Taiwan indigenous peoples from the Inō Kanori archive). One shows the man seated with a rifle and a Japanese flag; the other shows him directing soldiers with weapons and again carrying a Japanese flag. The editors of this volume argue, convincingly, that he probably fought on the side of the Japanese state against Han rebels in late 1895 and 1896 , as an irregular in the employ of Japanese station chiefs stationed near Quchi. ${ }^{66}$ His image was also reproduced on cabinet cards, a popular photographic medium from the 186 os through the 1890 s. $^{67}$

In contrast to the ethnically ambiguous Atayal photographs in the 1898 montage, Inō's canonical 1900 textual description of the Atayal describes them as facetattooed peoples, richly adorned in geometrically carved earrings and accessories that included buttons, brass, shiny metal, and colored threads. ${ }^{68}$ To reconcile the difference between Inō's textual/cartographic representations of bounded, discrete ethnic blocks among Taiwan's non-Han population and the motley assemblage of hybrid-themed photographs in the 1898 montage, Inō commissioned a color painting for the 1900 Paris Universal Exposition. ${ }^{69}$

The 1900 painting adds head-feathers, necklaces, hats, and earrings to each representative "savage type" to accentuate cultural differences among them. ${ }^{70}$ The process of fabrication is even more evident in the similarly augmented illustration for the 1907 Tokyo Industrial Exhibition, also curated by Inō. ${ }^{71}$ In the 1900 and 1907 exposition montages, the gun has been airbrushed out of the Atayal man's hand, large bamboo earrings have been painted in, and forehead and chin tattoos have been darkened or added. In the 1898 montage, the Bain News Service photograph, and the cabinet card, the facial tattoo on the man's forehead is invisible or barely visible, and the chin tattoo is obscured by shadow. An examination under high magnification of the high-resolution negative stored in the Library of Congress reveals a very faint forehead tattoo and rules out a chest tattoo. The photos of alternative poses from the same session show no evidence of visible facial or chest 
tattoos. Yet the reproduction in James Davidson's 1903 book (for which Inō Kanori was the ethnological advisor) exhibits pronounced forehead, chin, and chest tattoos, the result of doctoring. ${ }^{72}$

In the "ethnicized" 1900 and 1907 paintings, the female Atayal "type" shed her Chinese-style upper garment for an Atayal sleeveless vest, decorative chest embroidery, and a striped handwoven cape. The reornamented Atayal woman wears ethnologically correct earrings and necklaces, as well. Whereas the ethnicized male Atayal model was transformed with a paintbrush or pencil, his female counterpart was removed from the 1898 photomontage and replaced by a different sitter in the 1900 and 1907 composite portraits. ${ }^{73}$

As curator for the 1900, 1903, 1904, and 1907 expositions, Inō Kanori was charged with educating the public about the non-Chinese population of Taiwan. In the course of preparing the visual component of his exhibits, Inō turned "savages" into Atayal and other nondescript males into Yami and Paiwan by embellishing visual documents. It would be accurate to view these fabrications, in the context of colonial census taking, mapmaking, and museum curation, ${ }^{74}$ as exercises in top-down ethnogenesis.

\section{MAKING PHOTOGRAPHS IN QUCHI: VISUAL CULTURE AND TOP-DOWN ETHNOGENESIS}

James C. Scott's characterization of a parallel project in British Burma suggests that Inō's difficulties were not unique. As was the case with British officials, Japanese agents in upland Taiwan found even the act of naming tribes to be fraught with problems because of the hybridity they regularly encountered. Of these turn-ofthe-century classificatory schemes, Scott writes that "a major reason why traitbased designations of ethnic or tribal identity fail utterly to make sense of actual affiliations is precisely that hill groups themselves, as manpower systems, absorbed whomever they could. This absorptive capacity led to great cultural diversity within hill societies."75 These multiform, ethnically diverse "manpower-absorbing" societies were precisely the kind of formations Japanese officials encountered on the savage border circa 1900. In his study of the "Nanzhuang incident" of July 1902, Antonio C. Tavares observes that Saisiyat tribes under chieftains in the late Qing period were conglomerates of Han, non-Han, and hybrid actors, with hierarchies of power and wealth that ran counter to entrenched East Asian taxonomic spectra composed of descending markers of value from central and paramount hua (civilized) to peripheral and lowly yi (barbaric). ${ }^{76}$ Mori's 1902 description of Watan Yūra's extended family (whom Inō met in May 1897, pictured in figures 18 and 19) illustrates how, like the Nanzhuang operators, Wulai headmen adopted outsiders to create hybrid formations, to the chagrin of ethnic cartographers like Inō:

Wulai settlement's paramount chief Watan Yūra's eldest daughter Pazzeh and his adopted son [yōshi] are both about twenty years of age. This couple is the poken, meaning that if the line of succession is maintained, they will become chiefs . . ${ }^{77}$ 


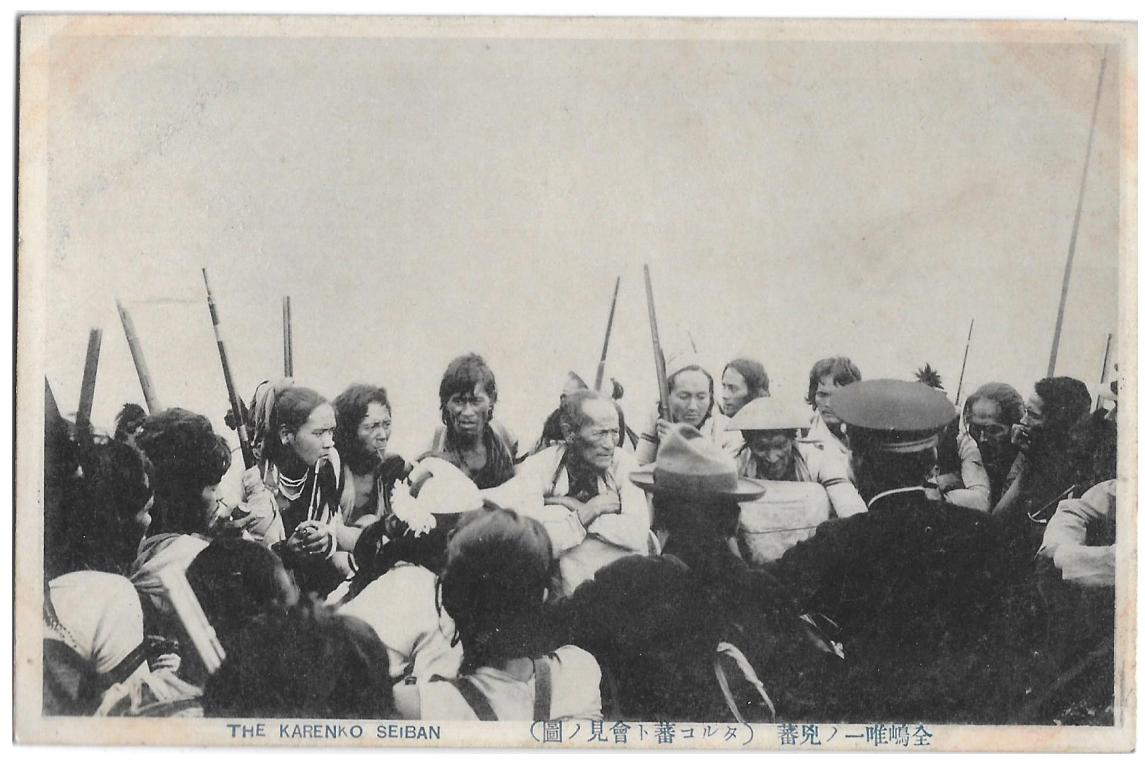

FIGURE 47. Photograph of Mori Ushinosuke, Japanese officers, and Truku headmen, 1910. Mori is facing away from the viewer and wears the dimpled hat. Courtesy of the Rupnow Collection.

To the right of Watan Yūra is standing a plains aborigine [peipozoku] (cooked barbarian [jukuban]) male without tattoos. About twenty years ago, it is said that he entered this settlement/village and became a savage brave [bantei] ... To the left are four wives of savages [banjin]. They are wearing Chinese-style blouses and gaiters. ${ }^{78}$

The networks that emerged through intermarriage, business dealings, armed conflict, and research among Japanese officials, ethnologists, merchants, and leading families from Quchi-we saw them in action during Inō's 1897 and 1898 information-gathering exercises-provided the setting for Mori Ushinosuke to make qualitatively superior photographs in the ethnographic genre. In contrast to our earliest examples of ideal-typical "head-hunting chiefs" photographed in Taipei studios (figure 21), the photographs made in Quchi during the establishment of the guardline were shot at or near the residences of the subjects (figure 19). The increased number of poses and more intricate stagecraft evident in the Quchi photographs suggest a heightened degree of familiarity between photographers and subjects. ${ }^{79}$ Mori himself was rarely photographed. One photograph was taken circa 1914 at the end of the Truku campaigns; Mori is wearing the hat, with his back toward the viewer (see figure 47).

In one recorded instance of Mori Ushinosuke's networking prowess, on January 28, 1903, Mori brought Rimogan resident Marai Watan and his wife Yūgai Watan to Taipei to view a local theater production of Ishiyama Gunki, meet the staff of the Taiwan Daily News, and see the sights. According to the short newspaper write-up, 
the Rimogan couple "came down from the mountains to visit Quchi town once or twice a year, but had never been to Taipei." ${ }^{\circ}$

Since Marai's portrait was displayed at the Osaka Exposition, which opened on March 1, 1903, it is reasonable to assume that Mori photographed this couple just before or after their visit to the capital city in January. Their most widely published portrait was shot in April 1903. It was included in a number of official publications and formed the basis for at least two picture postcard designs (see figure 59). Postcards were also generated from different poses of the same couple, indicating the ideological and commercial appeal of their likenesses as rendered by Mori's camera. ${ }^{81}$

Instead of using painting or drawing to "Atayalize" Yūgai, Mori was able to accomplish her racialization by requesting different poses. While Yūgai's anthropometric portrait shows her Chinese-style upper garments clearly, her more commercially reproduced pose was staged to present a more "authentic" Yūgai. ${ }^{82}$ In the latter photograph, she dons a cape of local design, which conceals her Chinese clothing. This de-Sinicized version of Yūgai's portrait showed up in various picture postcards, in a 1932 book by ethnographer Koizumi Tetsu, in a collection of government statistics, and on the sleeve for a set of Taiwan Indigenous Peoples picture postcards. ${ }^{83}$

During the over 150 days that it remained open, the Osaka National Industrial Exposition of 1903 drew over five million visitors. ${ }^{84}$ The Taiwan GovernmentGeneral lobbied intensively for exposition space under the energetic leadership of Gotō Shinpei. For Gotō, the Osaka Exposition presented an opportunity to educate Japanese on the home islands about the strategic importance of Taiwan, its potential economic benefits, and the cultural and culinary attractions of the island. A prevailing home-islander image of Taiwan, which Gotō hoped to dispel, was that of a savage place where demonic tribes practiced cannibalism. ${ }^{85}$ Against this backdrop, the "tattooed face savage" photos of men with large guns glaring at cameras in studio settings were hardly appropriate. Gotōs opportunistic aversion to savagery dovetailed with Inō Kanori's preference for cultural themes in evidence in the 1900 Paris Exposition painting. Thanks to Mori's new photographs from the environs upriver from Quchi, Inō was able to accommodate both desiderata without recourse to another commissioned painting. He simply exhibited Mori's photographs. ${ }^{86}$

Mori shot portraits of Pazzeh Watan, daughter of the headman Watan Yūra, near Wulai in February 1903, just after his January trip to Taipei with Marai and Yùgai. Pazzeh is seated to the viewer's far left in figure 19. This group portrait shows her wearing Atayal leggings with a Chinese blouse and headdress-a common sight along the old Qing savage border. This photograph appeared in a Taiwan Government-General publication of 1911, in the general-circulation magazine Taiyo in 1917, and in Mori's 1915 and 1918 ethnological picture albums, as well as on Shōwa-period picture postcards. ${ }^{87}$ It was also picked up for syndication in the United States. ${ }^{88}$ For a different pose, Pazzeh put on bamboo earrings, locally woven fabrics, necklaces, and a diamond-shaped breast cover festooned with white buttons for her anthropometric portrait. Her bust and profile from this shot appeared 
in dozens of formats in Japanese and foreign publications and continues to be reproduced to this day. The differences in Pazzeh's dress and ornamentation in the two portraits from February 1903 recall Inō's alterations of the 1898 montage discussed above: features considered to be signs of autochthony and distinction were accentuated, while any other visible signs of hybridity were obscured.

\section{THE VIEW FROM THE METROPOLE: CONSUMER DEMAND MEETS COLONIAL POLICY}

Photographs, as slices of time that freeze events, cannot narrate themselves without the help of external markers, such as captioning or juxtaposition with other photographs. ${ }^{89}$ In the case of Mori Ushinosuke's Quchi-area photographs, captions told various stories. The text for some portraits supported Mori's ethnicizing, pluralizing ethos. An early 19oos postcard of Pazzeh applied the caption "Shinkō [administrative district], Urai-sha [place name] Woman, Taiyal Tribe," sans terminology for "savage," for example. ${ }^{90}$

Mori's and Inō's original intentions were more often violated once they lost editorial control, because policy was moving in a different direction than representational practices favored by Japan's ethnologists. ${ }^{91}$ In December 1902, only a couple of months before Mori took Marai's and Pazzeh's photos for the Osaka Exposition, councillor Mochiji Rokusaburō, the brains behind Gotō Shinpei's aborigine policy, issued his famous "opinion paper on the aborigine problem," which averred that "sociologically speaking, they are indeed human beings (jinrui), but looked at from the viewpoint of international law, they resemble animals (dobutsu no gotoki mono)."92

As the scorched earth campaigns were commencing, in June 1904, parliamentarian Takekoshi Yosaburō arrived in Taiwan to write a progress report. ${ }^{93}$ In September 1905, Takekoshi published Taiwan tōchi shi, his encomium to Japanese rule based on his 1904 visit; he included profile pictures of Watan Yūra's daughter Pazzeh Watan, who figured prominently in Mori's Quchi photographs, as a nameless Atayaru-zoku jo (Atayal tribe female) next to exemplars from each officially recognized tribe. Most of these photographs were also exhibited at the 1903 Osaka Exposition. These ethnically labeled profiles and frontal shots, with blank backgrounds in the anthropometric genre, were interleaved with photos of Japanese military maneuvers and Gotō's inspection tour of camphor forests. In this context, the ethnicized portraits of Marai and Pazzeh appeared as emblems of recalcitrant Atayals, marked as an expendable race. In contrast to the photographed Jiaobanshan emissaries who arrived in Taipei in September 1895 to initiate relations between the government-general and the cismontane Dakekan tribes, the names of Watan, Marai, Pazzeh, and Yūgai were not mentioned in newspaper accounts of guardline movements in and around Quchi. And by the time their photos emerged in the flood of picture albums of Taiwan indigenes published in 
the 1910s, Japanese publicists and anthropologists had ceased attaching personal names to photographs of indigenes altogether.

During the era of the guardline, 1903-1915 (see chapter 1), the rhetoric on Atayal savagery was amplified and reinforced by the captions for various contemporary postcards that identify Pazzeh Watan as a seiban, bellicose seiban, or (incorrectly) as a member of the Taroko seiban, the most militarily resistant subgroup of Atayal peoples. ${ }^{44}$ This view received the imprimatur of the Taiwan Government-General, which issued its second set of commemorative postcards on October 15, 1905. One featured a studio portrait of armed Atayal men captioned as "head hunters" in English and labeled "Taiwan savages" (Taiwan banjin) in Japanese. ${ }^{95}$

The government-general would issue three more commemorative postcards featuring indigenes during the guardline period. Martial themes were prominent. The 1908 set, for the thirteenth anniversary of colonial rule, commemorated the Stone Gate Battle of 1874 with a colorful painting of the battlefield and a tombstone to the fallen warriors. ${ }^{96}$ A paired card reprised an 1874 photograph of Saigō Tsugumichi surrounded by his own soldiers and several emissaries from Paiwan villages in Hengchun (figure 8).

These cards were issued two years into the administration of Governor-General Sakuma, who himself was the hero of this 1874 battle. The fourteenth-anniversary card (1909), issued on the eve of Sakuma's "five-year plan to conquer the aborigines" (see chapter 2), features the governor-general himself. Whereas his fellow veteran of the 1874 campaign Saigo sits among his Paiwan emissaries in the 1908 commemorative series, Sakuma is elevated high above the more than forty Atayal and Saisiyat men and women gathered at his residence in the photo from the 1909 series. Sakuma is placed even higher than Prince Kan'in, who was conducting a royal tour in 1908.97

To look at the body language and positioning of Paiwan and Jiaobanshan sitters (figure 37) in their respective commemorative photographs, one might surmise that they were guests, or at least subordinate allies, at functions presided over by Saigō or Kabayama (in 1874 and 1895, respectively). But the fourteenth-anniversary photograph of Governor-General Sakuma allows for no such reading. Here, even the most highly placed indigenous person's head is even with Sakuma's feet, while most of them are huddled on the ground in positions of abjection. In fact, the 1909 postcard can be read as the wish fulfillment of the Füzoku gahō artist who imagined Kabayama in a similarly commanding position over the Jiaobanshan emissaries in 1895 (figure 36).

The last of the guardline-period TGG postcards with indigenous themes was transitional. It struck a balance between a pluralist sensibility and the discourse on savagery (see figure 48). Issued in 1911, at the height of the war against Atayal peoples in and around the tramontane Dakekan tribes, it included a Mori Ushinosuke photograph of an Atayal dwelling and attached granary..$^{98}$ This scene was common in anthropological reports of the time. The card also featured a well-circulated photograph of Koalut dancers from Hengchun. ${ }^{99}$ The photographs were innocuous 


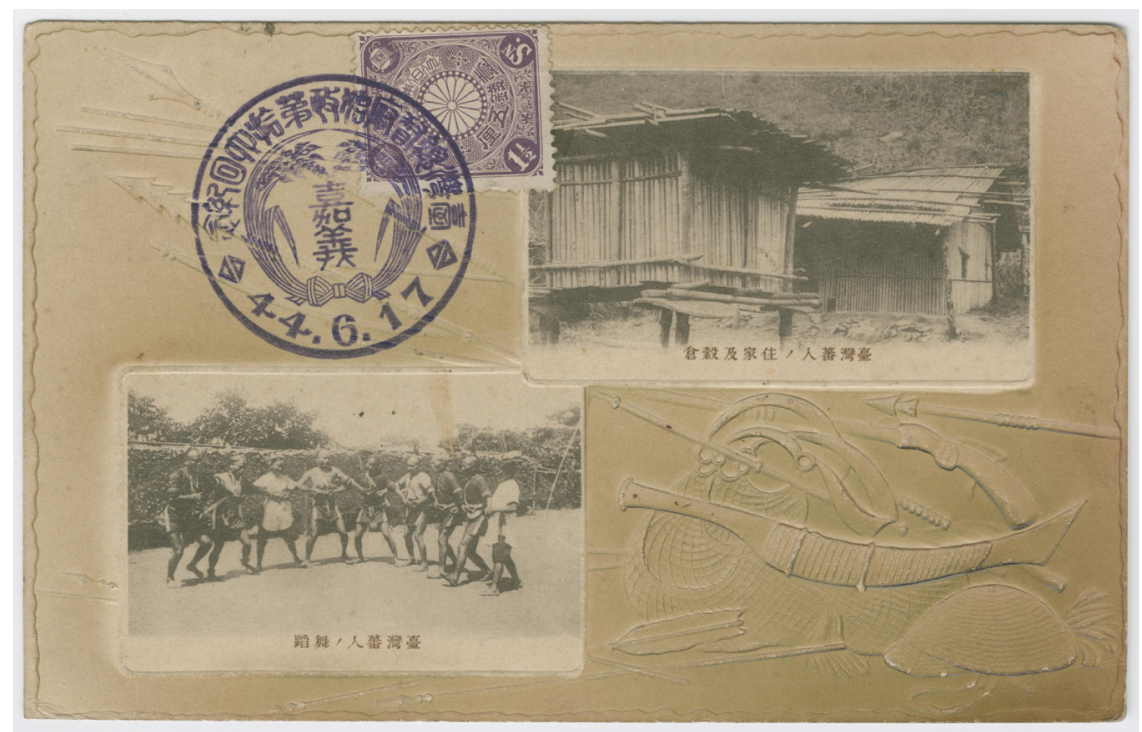

FIGURE 48. Official commemorative postcard depicting indigenous customs, 1911 ["Taiwan Aborigines Dancing” and “Taiwan Aborigine Dwelling with Granary"], ip1441, East Asia Image Collection, Lafayette College, Easton, PA, accessed May 13, 2016, http://digital.lafayette.edu/ collections/eastasia/imperial-postcards/ip1441.

enough, but they were framed by a heavily embossed decorative element composed of a machete, a head-hunting backsack, a gun, some spears, and two arrows, next to a trademark Atayal wisteria-woven cap. The composition therefore connoted menace, if not danger. At the same time, it presupposed its audience's familiarity with particular cultural repertoires of the Atayal and Paiwan indigenous ethnic groups, so that viewers could read the embossed icons as symbols of indigenous bellicosity. Assuming that these mass-produced, high-quality commemorative sets were designed with great deliberation, one can conclude that the pluralistic terminology and iconography so laboriously engineered by Inō, Mori, and a cast of hundreds was gaining traction at the apex of administration in Taiwan by the 1910 s, if only incrementally. The photo captions in figure 48 themselves are mute regarding ethnic designation and retailed generic words for "savage" instead.

The predominance of head-hunting and savage tropes in the governmentproduced postcard sets and in the state-produced and commercial punitive expedition albums reflects the power of metropolitan policy directives and consumer tastes to shape the meanings attached to widely circulated photographs of Taiwan's indigenous people. With adroit captioning and the creative deployment of design elements, Tokyo and Taipei publishers and editors yoked print culture to TGG policy and Japanese consumer tastes. At the same time, ethnologists on exposition-planning committees, editorial boards of academic journals, and lower-level 
corners of the colonial bureaucracy launched counterhegemonic arguments with artifacts, photographs, drawings, and texts. To be sure, advocates of a pluralist agenda such as Inō Kanori and Mori Ushinosuke were largely motivated by concerns of professional advancement in the emergent field of anthropology. They also had an eye for the survival and growth of the discipline itself. The ethnologists pursued these ambitions as they extolled Japan's modernity in the global arena of scientific publication. Whether they supported the discourse on savagery or ethnicity, the poses, set designs, captioning, and layout decisions that shaped visual culture surrounding indigenous peoples responded to dictates largely divorced from the specific locations where sitters, photographers, and stage managers came together to expose wet- or dry-plate slides to light in the presence of living beings and the environment.

To ground these images in their historically specific contexts of creation, we must return to the Atayal-dominated regions of Quchi and Jiaobanshan-each a fecund hearth of pluralist and savage-trope imagery in the early twentieth century. If indigenes themselves had anything to say about how they were being represented in Japanese photography, they exercised agency at these sites.

\section{THE SAVAGE-BORDER MISE-EN-SCENNE OF COLONIAL PHOTOGRAPHY IN TAIWAN}

In May 1903, two months after the opening of the Osaka Exposition and the first public display of Watan Yūra's family portrait, Japanese authorities imprisoned nine Quchi men. They were used as hostages to secure the cooperation of other Quchi leaders to build a cordon sanitaire to separate camphor fields and tax-paying settlements from Atayal who were attacking camphor harvesters. This stratagem met with some success. During the years 1904 and 1905, the local knowledge, military prowess, and political agility of Quchi residents made it possible for the Taiwan Government-General to establish the toehold it needed to build its guardline across the most contested areas just south of Taipei. Thereafter, from its Quchi base, the government-general built several hundred miles of guardline across northern Taiwan. ${ }^{100}$

The role of Quchi auxiliaries in the advancement of the guardline is attested by two photographs produced there circa 1905. One depicts an extended family, consisting of eleven men, four women, and two children (see figure 49); the other depicts seven armed men (see figure 50), who also posed for the family portrait in figure 49. The brush-written caption to the extended family portrait places the scene at the "Guardline Control Station," meaning that it was taken in 1904 at the earliest. It was reproduced in the September 2, 1905, Taiwan nichinichi shinpō (Taiwan daily news). Therefore, the men, women, and children captioned as "Wulai Savages" in the newspaper were photographed about two years after Mori's famous Quchi photographs were shot in early 1903. 


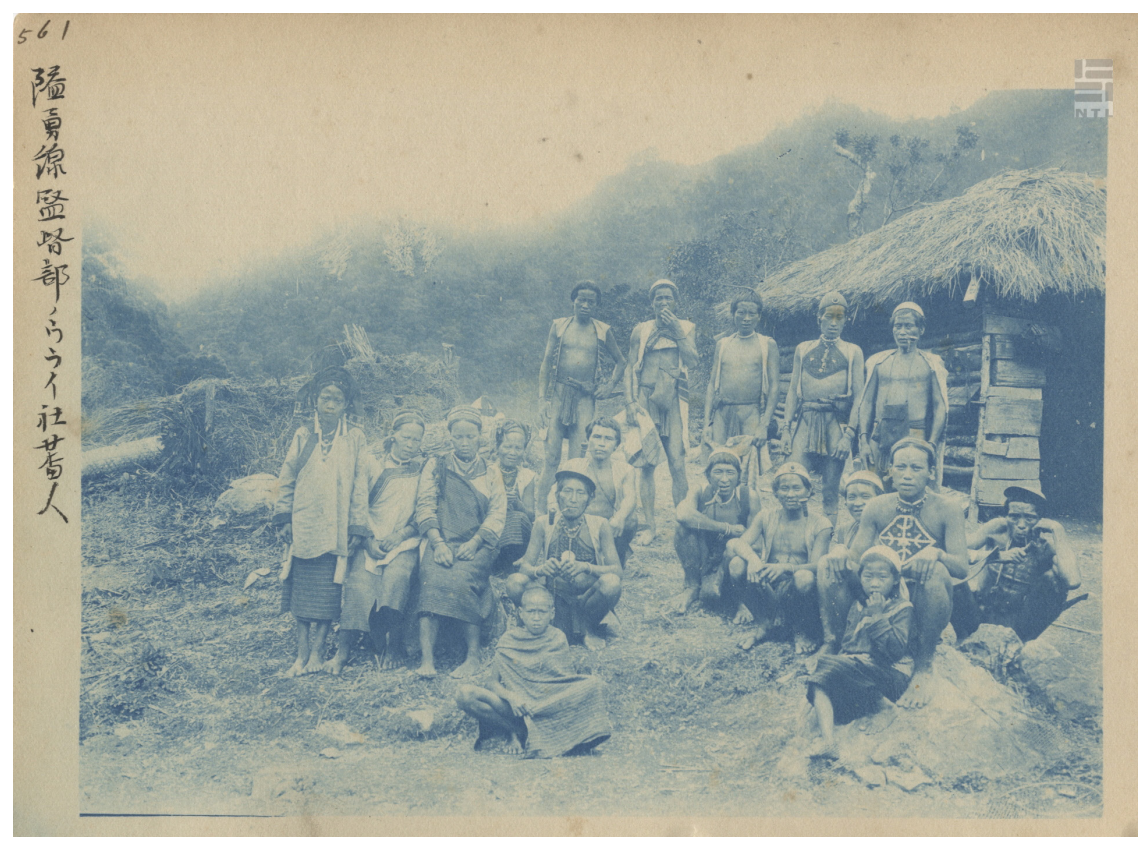

FIGURE 49. Men and women along the Quchi guardline, ca. 1904. Courtesy of the National Taiwan Library (Taipei). Unpublished photograph album, Taiwan shashin (National Taiwan Library Document 0748-71, plate 82).

The "family snapshot" (figure 49) appeared on an early 190os postcard, in a few Japanese-language books, in several foreign publications, and in geography textbooks. ${ }^{101}$ A comparison of the careers of the 1903 (figure 19) and 1905 Wulai (figure 49) group portraits suggests that a threshold was crossed in 1905 with the militarization of relations between the Japanese government and the Quchi-area tribes. In each group portrait, four women crouch to the viewer's left, dressed in a combination of Chinese and Atayal clothing. Standing and squatting men with pipes and diamond-shaped breast ornaments are the center of attention. Children wrapped in trademark striped Atayal capes sit in the foreground of each portrait, rounding out the cast of characters. However, the structure in the background of the 1905 photograph (figure 49) is new. This distinctive feature is a guardline control station. This military installation is not identified in the published versions of the photo, although it is indicated with a hand-brushed caption in an unpublished album housed in the former TGG library in Taipei. Therefore, editors and consumers likely viewed figure 49 as a family portrait rather than as the war photograph that it was.

In the seven Japanese-language publications that include a photo from the 1905 shoot (figures 49 and 50), only the mixed gender and age "family portrait" 


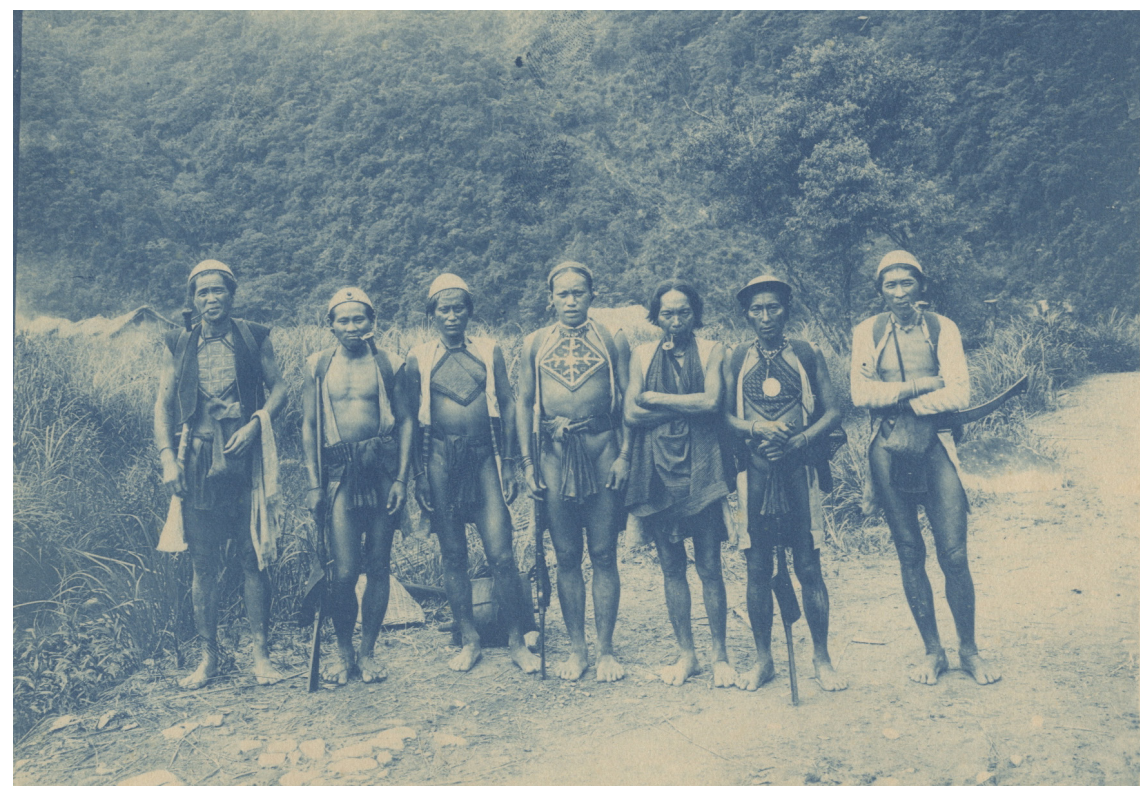

FIGURE 50. Japan's Atayal allies along the Quchi guardline, ca. 1904. Courtesy of the National Taiwan Library (Taipei). Unpublished photograph album, Taiwan shashin (National Taiwan Library Document 0748-71, plate 102).

appears. In the 1905 and 1906 versions, the sitters are referred to as "Urai [Chinese: Wulai] tribe" people, but in the 1907, 1912, 1925, 1928, and 1933 versions, they are captioned as members of the Atayal tribe. Thus, in Japanese-language publications, the 1905 photograph of a large group in front of an unacknowledged guard station (figure 49) was captioned to ethnicize the Atayals. This framing operation was simultaneously culture-affirming and detemporalizing vis-à-vis the photograph's sitters.

In contrast, of the four English-language publications (two by Japanese publishers for foreign consumption, and two by foreigners) that picked up the 1905 shots, three adopted more explicitly martial photos of the armed men in the road (figure 50). These publications also used the term Atayal to describe the sitters-in 1910, 1916, and 1923. Based on this analysis, we can say that somewhere between 1906 and 1907, the term Atayal began to catch on with publishers, even for photographs that did not obviously illustrate the unique folkways of the sitters but instead lumped them together with the world's garden-variety savages with guns.

In sharp contrast to the shot of seven armed men blocking the road in the 1905 series, the spin-off photographs from the 1903 portrait (figure 19) eschew martial themes in favor of domestic scenes of cloth production and residential 
architecture. Mori took several photographs, besides the family portrait of Watan Yūra, during the same session. These scenes from daily life circulated widely as postcards and illustrations for a variety of publications. ${ }^{102}$

Mori Ushinosuke's Quchi-area photos, comprising subjects from Wulai and Rimogan, were reproduced in at least forty different postcard designs and in dozens of newspapers, magazines, journals, and other media in subsequent years. ${ }^{103}$ While Mori the ethnologist may have reached dozens of anthropologists through his reports in the Journal of the Tokyo Anthropological Society or thousands of readers through his serialized travelogues in Taiwan newspapers, the audience for his photographs of representative Atayal culture bearers was global.

There are many reasons why the period 1903-05 was propitious for mass-circulation Atayal photographs. First, by the time Mori arrived in late 1902, a network of acquaintances connected him to several sitters and photographic sites. Therefore, as the multiple poses and variations in the Rimogan shots indicate, Mori was able to work in a better climate for photographic production than his predecessors Torii and Inō, who both operated on tight schedules among unfamiliar peoples during their forced-march surveys of the late 189os. The state of photographic technology at the time demanded long exposure times and the participation of willing sitters to produce high-resolution, interesting, and well-composed photographs. During the period 1902-05, many Quchi people were on the government's payroll or employed by Japanese industry. Quchi residents may have charged money to be photographed, as well (a common practice a little later on), or they may have been favorably disposed toward their Japanese trade partners, employers, acquaintances, and in-laws (such as men like Jiku Shō Min).

Second, just after Mori's prints from Quchi began to arrive in Osaka for the exposition and in the Tokyo University anthropology lab for analysis, a picture postcard boom was ignited by the Russo-Japanese War. The clearest and best extant copies of the Quchi photos, the Wulai guardline photo, and even one copy of the Jiaobanshan emissary photo are in the form of collotype prints on sturdy postcard stock. In the 1903-07 period, several postcard producers availed themselves of Mori's photographs and other official sources to propagate these highquality reproductions. Textbook publishers raided this storehouse to represent indigenous Taiwan to every grade-school student in Japan.

However, not long after these iconic individual and group portraits were shot between late 1902 and early 1903, local Quchi men overran Taiwan's first hydroelectric power station and killed fifteen workers and guards in $1905 .{ }^{104}$ The razed power station was built on the Xindian River near Quchi village under the direction of Dogura Ryūjirō. ${ }^{105}$ Dogura was an intimate of Jiku Shō Min and Mori Ushinosuke. He had also obtained the rights to develop hundreds of hectares of Atayal land around Quchi for camphor production in 1899. The termination of official photographic activity in Quchi coincides with these events, unsurprisingly. 
The reprisals for the 1905 incident must have been harsh, though details are hard to come by. We know that within a very short time, Wulai was transformed into a hub of Japanese assimilation policies and hot-springs tourism. In December 1908, travel writer and explorer Mary T.S. Schaffer and three Canadian companions visited Wulai to get a glimpse of the world-renowned "head-hunters of Formosa." Like many a visitor after her, Schaffer wrote excitedly about the prospects of meeting a savage head taker and even purchased a postcard of a freshly taken head held by its exultant killers. But when she actually met Atayal people on the trail, she found them to be friendly and happy to pose for photographs in exchange for silver coins. Included in Schaffer's collection of magic-lantern slides was a colortinted profile of Pazzeh Watan, the daughter of Watan Yüra (the woman in figure 19 , to the viewer's far left). ${ }^{106}$ U.S. Consul to Taiwan James Davidson also used colorized glass-lantern slide images of Mori's sitters for his public presentations. ${ }^{107}$ In fact, all of Schaffer's and Davidson's photographs were created before 1905, when Wulai was still ethnologically available, so to speak.

The period 1903-05, then, was a window in time. Mori arrived in Wulai late enough to benefit from the networks established by Inō, Jiku, Dogura, and Watan Yūra, and from recent advances in camera technology, but early enough to ride the wave of the Russo-Japanese War postcard boom. The luck of good timing also allowed Mori to make photographs before the 1905 attacks on the power station flipped over the chessboard of frontier diplomacy along the Xindian River south of Taipei.

\section{PUNITIVE EXPEDITION PHOTO ALBUMS}

The period between the 1905 Quchi incident and the establishment of an ethnic tourism industry in Jiaobanshan in the early 1920 s marks a transitional period in the politics of geobody construction in Taiwan. During this epoch, a plethora of "punitive expedition" photo albums and picture postcards of war imagery from the guardline dominated the photography of Atayal peoples. ${ }^{108}$ Superficially, the preponderance of combat, logistics, and scenes of encampment would suggest that the pluralistic imaginary developed by Inō, Torii, and Mori was losing ground during the run-up to World War I. ${ }^{109}$ However, second-order geobody construction in fact consolidated itself, oddly enough, in part through the circulation of war albums. While some of these guardline-focused albums eschewed the use of ethnonyms and culturally pluralist maps, others enshrined indigenous ethnic categories and normalized them by prefacing the narrative portions of their accounts with thumbnail sketches of Taiwan's ethnographic complexion. This representational strategy-which situated dynamic, eventful, and individualized photographic portraiture in a framework that presented such images to readers as illustrations of timeless ethnic traits-would continue in Taiwan to the end of colonial times. 
In all such productions, which could run to over six hundred pages, the author begins the account with an atemporal, spatially organized discussion of Atayal, Saisiyat, Paiwan, Tsou, Bunun, Amis, Tsarisen/Rukai, Puyuma, and Yami social organization, material culture, ritual practices, religion, and language. These sketches are prefaced by a map that locates each second-order geobody and arrays them like nation-states on a Mercator projection. Photographs from the Mori and Inō storehouse and others in the same genre then illustrate the features of each group. The second part of such publications, beginning with war albums in the 1910s, proceeds to narrate the movement of the guardline and Japanese troops into the interior of Taiwan. Major battles are recounted, statistics of "territory mastered" are inserted. In this process, the hard-and-fast line between indigenous Taiwan and Han Taiwan was naturalized, along with the ethnic topography proposed by Inō in his 1900 Taiwan banjin jijō (Conditions among Taiwan's savages). This pluralizing operation worked in tandem with images and texts that paradoxically celebrated a war that portended to wipe out the cultures so lovingly portrayed between the same covers. Narita Takeshi's 1912 album, Taiwan seiban shuzoku shashinchō (Savage tribes of Taiwan photo album), set the tone (see figure 51).

Narita's map depicts two competing logics. Its slightly smaller inset map classifies space (Thongchai's definition of territorialization) according to its degree of submission to the colonial government. The legend associates different colors with varied military and civil conditions. The endpoint of the trajectory implied by the dynamic categories "half-submitted," "reluctantly submitted," "completely submitted," and "completely unsubmitted" is a fully "submitted" Taiwan. Narita's larger map partakes in a different temporal logic. It depicts Taiwan's indigenous ethnic groups as a system of second-order geobodies. These static categories and polygons, which were retained in dozens of official and commercial maps into the 1940s, depicted Taiwan as an eternally and essentially multiethnic geobody. The dynamic and static portraits of indigenous spaces, however, had one thing in common: the indigenous, non-Han portion of Taiwan was separated from Han Taiwan by a one-dimensional boundary line, the one depicted in figures 39 through 41.

By 1912 Narita's map could truthfully depict Quchi and Wulai as "completely submitted." However, there was an even more compliant classification, which was reserved for the Amis in the eastern rift valley, the Puyuma, and the tribes of lower Hengchun: taxable regions under normal administration. In other words, by 1912, it was possible to be classified as an indigenous tribe even if every single member of an ethnicity's second-order geobody was already a tax-paying Taiwanese subject, living in the normally administered area. Such was the case with the Amis, whose designator does not appear in 1930s statistical studies of indigenous political economy and demography. Nonetheless, the Amis' putative living space was coded as a second-order geobody and solidly colored apposite other ethnic groups on prefatory maps to these compendia. ${ }^{110}$ Thanks to their traditions of surplus wealth production and historical familiarity with a commoditized economy, it was 


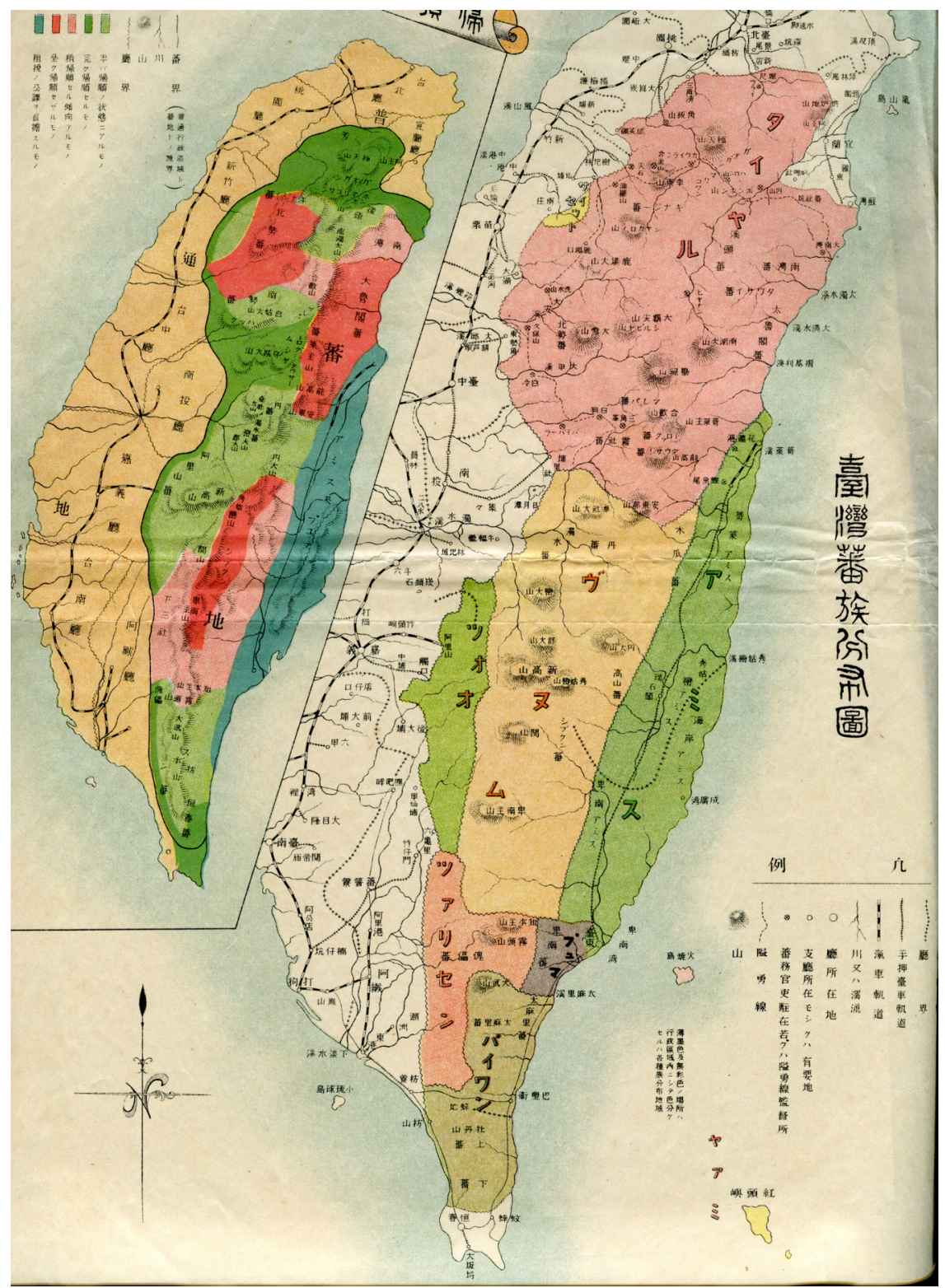

FIGURE 51. Dynamic and static maps of Taiwan's ethnic diversity, ca. 1912. Narita Takeshi, Taiwan seiban shuzoku shashinchō (Taipei: Narita shashin seihanjo, 1912), n.p. 
possible for the Amis peoples, as well as the Tuilasok, Koalut, and Sabaree Paiwan, to move out of the "special administration" category during the first decade of the twentieth century under Japanese rule. However, the colorful polygons that marked out their separation from Han-dominated Taiwan on mass-produced, scholarly, and official ethnic maps never budged.

Over the course of Japanese rule, static ethnic maps resembling figures 2 through 4 and figure 41 were reproduced millions of times in photo albums, on picture postcards, in school textbooks, and in newspapers for public consumption in Taiwan, in Japan, and around the world. In short, while Japanese military pacification and police occupation among the Atayal, Sediq, Truku, Tsou, and Paiwan succeeded to a level unprecedented in Taiwanese history, the movement of the Qing-period savage border in concert with settler encroachment, assimilation, and state aggrandizement was finally arrested under the Japanese regime in the 1910s.

Although more punitive expeditions and forced relocation campaigns were yet to come, the notion that "special administration" in indigenous Taiwan was a temporary expedient went extinct. Administrators, scholars, and imperial subjects came to view all indigenes, no matter their outward signs of assimilation, as members of aboriginal ethnic groups that lived beyond the pale of dynamic capitalist political economy. This vision of indigeneity turned out to be a self-fulfilling prophecy.

\section{ATTACHING PHOTOGRAPHS TO MAPS: THE CULTURAL INVESTMENT OF SECOND-ORDER GEOBODIES}

In 1905, the year of the Atayal raids on the Quchi power station, the governmentgeneral cut off and surrounded Jiaobanshan, the other site of serially reproduced Atayal imagery, with fortified guard posts, clear-cut fields to aid in the detection and shooting of indigenes, and electrical wire. In 1906 Governor-General Sakuma Samata took the reins and turned up the pressure on Atayal peoples who resisted the commoditization of forest lands and subordination to a bureaucratic surplus-extracting state. Government forces embargoed recalcitrant Jiaobanshanarea tribes into surrendering their weapons by extending the guardlines into the interior. The last push culminated in a 107-day Chintōzan campaign that cost hundreds of dead on either side. ${ }^{111}$ In local memory, the 1907 battle is considered the beginning of Japanese rule in Jiaobanshan (today's Fuxing Municipality in Taoyuan Prefecture). By 1925 the former hot spot in the camphor wars had become a show village for indigenous culture, despite its minority indigenous population. Jiaobanshan's transition from battleground to ethnic theme park, it could be argued, presents a microcosm of the island-wide processes that secured the indigenous habitations of Taiwan as second-order geobodies.

In 1908 the main trunk railway line from Jilong to Gaoxiong opened. This feat of civil engineering was the first step in the creation of a robust ethnic-tourism industry in Taiwan, though it would take years to mature. The numerous colonial 
railway and commercial tourist guides that followed the completion of the trunk line provide us with a window into the transformation of Jiaobanshan from ungoverned space to accessible ethnic resort town. The only Atayal person to appear in an early 1908 guide occupies the corner of a montage. The text surrounding the illustration describes the loss of Japanese life in a massacre near Beipu, the site of a major uprising in 1907. In jarring contrast to later guides, this pamphlet only mentions indigenes in connection with the establishment of rural garrisons, guardlines, and reclamation projects. ${ }^{112}$

In 1910 a light-gauge pushcart railway connected the walled city of Dakekan to formerly inaccessible Jiaobanshan; it was by far the most expensive and lengthy rail extension of the year's "savage territory" improvements. ${ }^{113}$ This railway fed supplies and troops to Jiaobanshan for Japanese military actions against the tramontane Dakekan settlements known as the Gaogan tribes (an Atayal people). Endō Hiroya's Banhi tōbatsu kinen shashinchō (Aborigine punitive expedition commemorative photo album), dated 1911, features photographs of Jiaobanshan town occupied by Japanese soldiers and policemen. The main road is littered with military infirmaries. A few "Jiaobanshan banjin" are pictured standing next to policemen (see figure 52). ${ }^{114}$

Late 1910 marked the end of large military maneuvers against Gaogan. By 1912 Jiaobanshan was sufficiently pacified to be considered the site for a visit from the Meiji emperor himself. For the emperor's expected visit, a special reception hall, later depicted in numerous picture postcards, was erected in the main settlement area. ${ }^{115}$ But, as a privately produced 1915 travel guide reminded its readers, even though the area was undergoing reclamation and the population was increasing, the next stop, Gaogan, was still garrisoned for defense against indigenes. ${ }^{116}$

Just after this 1915 guide appeared, Jiaobanshan became an obligatory stop on imperial inspection tours of Taiwan. The Imperial Household Ministry archive in Tokyo contains several lavishly illustrated albums of these tours, which included those of Prince Kan'in in 1916, Crown Prince Hirohito in 1923, and Prince Chichibu in 1925. During this liminal decade, the Japanese royals affixed commercial photographs and their own snapshots to keepsake albums. The overall impression is of Jiaobanshan as a borderland that was fast becoming an indigenous theme park.

By 1920, the light-gauge pushcart railway that connected the town of Jiaobanshan to the railway stop at Daxi (the new name for Dakekan) had become a conduit for tourists, freight, and officials. Travelers ascended the mountain pushed by two Taiwanese laborers, with rest stations and inns all along the way. ${ }^{117}$ A 1921 travel guide emphasized the scenery and the pushcart ride. It also created the boilerplate for subsequent Jiaobanshan descriptions in the official travel guides:

Nine $r i$ and seven cho southeast of Daxi [Dakekan] walled city is the savage border. If you clamber your way up, you'll be able to intimately inspect conditions among the aborigines. This area is zigzagged and steep. Climbing up the mountain path by tramway is extremely slow, but descending is extremely fast, for a speedy return. At the 


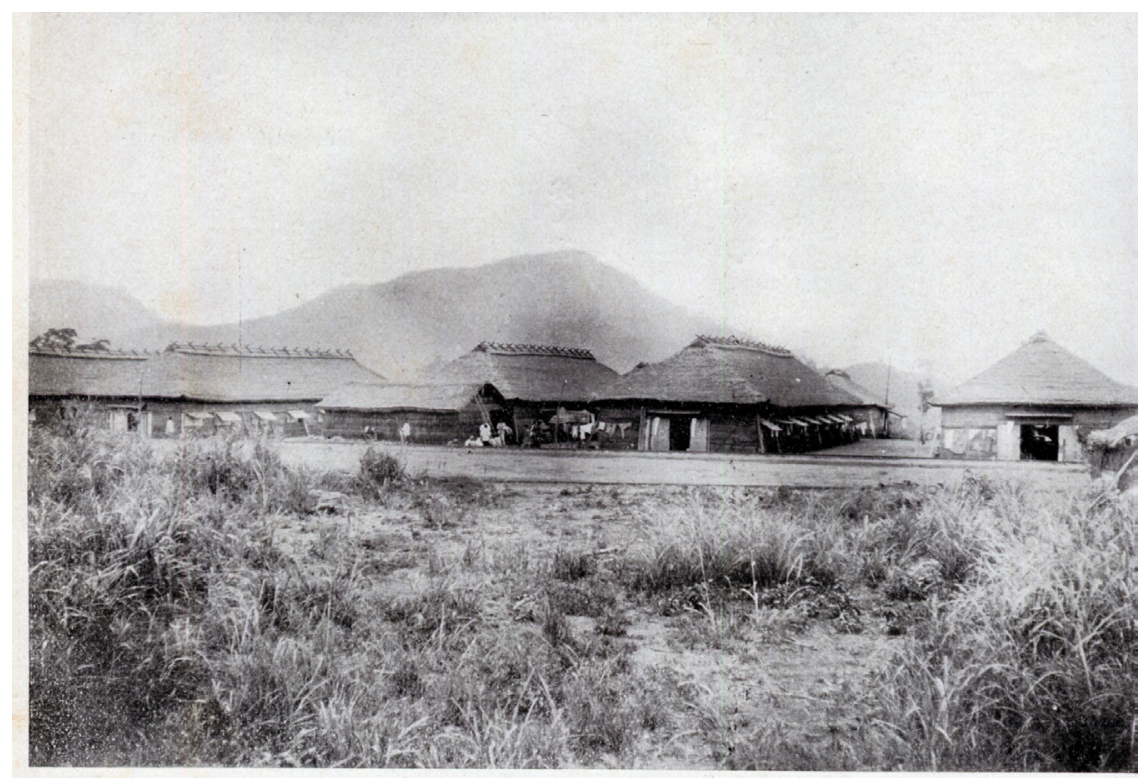

望違ノ臺砲山頭枕站舍颜ノ隊中口出造派山板㑇廳園桃

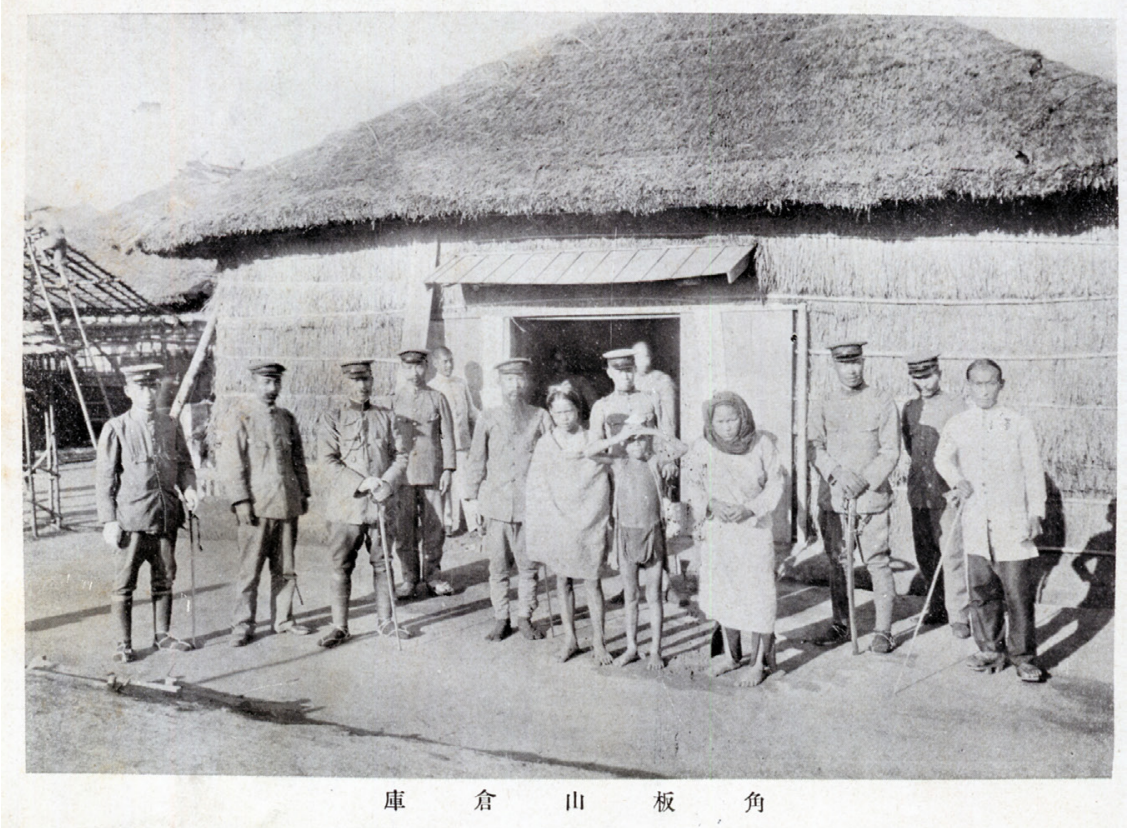

FIGURE 52. Jiaobanshan as staging area for Gaogan offensives, ca. 1910. Endō Hiroya, ed., Banhi tōbatsu kinen shashinchō (Taipei: Endō shashinkan, 1911), n.p. 
top of the mountain, things suddenly open up into orderly quadrilateral residences; this is Jiaobanshan. There is the balmy fragrance of camphor and the reception hall built from building materials from Arisan. This area is a tableland that commands a view upstream of the Dakekan ravine and is ringed by verdant linked ridgelines.... It is thus known not only for its steep terrain but also for its spectacular scenery. ${ }^{118}$

Sōyama Takeshi writes that "indigenous territory" tourism had become a mainstay by 1924 , when the "injuries from indigene violence" had finally subsided and railways extended to the interior. ${ }^{119}$ The 1924 version of the railway guide boasted that Jiaobanshan was not only a "strategic hold in aborigine administration" but also the site of two Japanese inns, a police station dispatch office, a post office, a school for aborigine children (figure 27), an aborigine trading post (figure 30), a Mitsui Corporation outpost, and a camphor company collection depot. The guide also mentioned that visitors could pick up valuable indigenous manufactures at good prices. Jiaobanshan, concluded this entry, could not be overlooked as a place to "get to know the aborigines." 120

Jiaobanshan's reputation even extended to the rare foreign visitor. In 1925, H. L. Bagallay of the British Foreign Office described Jiaobanshan as "a 'show village" about twenty-five miles from the capital, where 'tame' savages are exhibited to official visitors and tourists ... " ${ }_{121}$ The 1927, 1930, and 1934 Taiwan Railway guides repeated the 1924 description above, suggesting that ethnic tourism had become routinized in Jiaobanshan by the early 1930 s. $^{122}$

The 1934 guide adds that Jiaobanshan, Wulai (see above), and Alishan, all sites for indigenous tourism, were now in "normally administered territory." However, the official 1935 Indigenous Household Register statistics indicate that all Atayal and Tsou peoples-the indigenous peoples of these three sites-resided beyond administered territory. Therefore, tourists were actually chatting with and photographing indigenes who were either visiting the tourist sites as employees or who had removed to the normally administered territory. ${ }^{123}$ In these three popular sites, tourists could have the best of both worlds. They could enter Jiaobanshan, Wulai, or Alishan without filling out burdensome paperwork and paying extra fees required to travel beyond the line between special and normal administration and "experience savage life" without unduly upsetting their tour itineraries. ${ }^{124}$ Ease of access and proximity to civilization were indeed the major themes in touristic imagery of Jiaobanshan in the 1930s. Photos of Japanese schools (run by police officers) filled with indigenous children and Hinomaru flags decorated magazines, atlases, and picture postcards of the 1920 s and 1930 (figure 31). Much of the textual rhetoric accompanying these images extolled the conversion of a former head-hunting people into rice-growing, peace-loving subjects of the emperor.

Recall that in 1895, culturally hybrid figures-the Atayal woman Washiiga in a Chinese blouse or the Atayal man $\mathrm{Pu}$ Chin wearing a queue-were prominent in Japanese imagery because interpreters were the point of access to Jiaobanshan. Anthropologist Inō Kanori, in 1896, abstracted a photograph of Jiaobanshan 
residents taken in built environments by whiting out its background to produce more suitably anthropological types. Into the 1910s and even the 1920s, Chinese blouses like Washiiga's were prominent in photographs of Atayal women in borderland junctions such as Jiaobanshan or Wulai, as exemplified by Mori Ushinosuke's photo of a "Dakekan tribe woman" in July 1906, at the height of the camphor wars near Jiaobanshan, and by dozens of picture postcards. ${ }^{125}$ By the 1930s, however, Chinese blouses were scarce in Japanese photography, while Japanese garments became commonplace. For ethnic-tourism operators, the question became how to balance the messages of progress and exoticism by packaging accessible villagers as avatars of a more primitive and even timeless past.

One answer was found in the skillful use of graphic arts to construct Jiaobanshan as a gateway into the Atayal geobody. This effect was achieved by manipulating particular icons of Atayal ethnicity such as facial tattoos, tobacco pipes, back-strap looms, and wicker backpacks. These icons of the unique Atayal cultural repertoire were detached from lived environments, bundled together, and marketed as portable keepsakes from an unspoiled corner of the savage territory. On a circa 1930 postcard, a woman's facial tattoos, wicker backpack, and pipe were all logoized in such a fashion (see figure 53).

The sitter for this postcard image is also the mascot for the sleeve that houses a set of eight Jiaobanshan postcards (see figure 54). Like Washiiga, Habairon, and Marai in the 1896 anthropology journal (figure 39), this woman was rendered into line art and then imaginatively placed in a new setting. But instead of the background that corresponded to blank space on the 1905 census map (figures 33 and 39), the Wakayama Prefecture-based Taishō Company placed her in front of a mountain range and Jiaobanshan's trademark suspension bridge. Tourists walked single file along this popular attraction, which connected the souvenir stands and the model school for indigenes to the mountains. The sitter in figure 53 was photographed in front of a fence and a neatly edged footpath on level ground, presumably in Jiaobanshan's model ethnic village. The graphic artist thereafter transformed her into a highlander guarding a secret passageway for the postcard sleeve titled Bankai no hikyō (Undiscovered savage border).

Advances in reprographic technology allowed for further abstractions and mash-ups. This sitter's tattooed face, as well as her backpack, were logoized into monochrome stamps that adorned other cards in the set, tying otherwise placid scenes that connoted settled life and domesticity to the tattooed mascot who greeted visitors to the mountainous and supposedly mysterious savage territory (figure 55). The photographs on the cards themselves depict an enclosed, flat settlement composed of Japanese-constructed dwellings and public buildings. But the last card in the set (figure 56) depicts the setting, much like the sleeve, as an extension of Taiwan's central cordillera, rather than as the island's most convenient place to sample indigenous culture in the course of a weekend tour. 


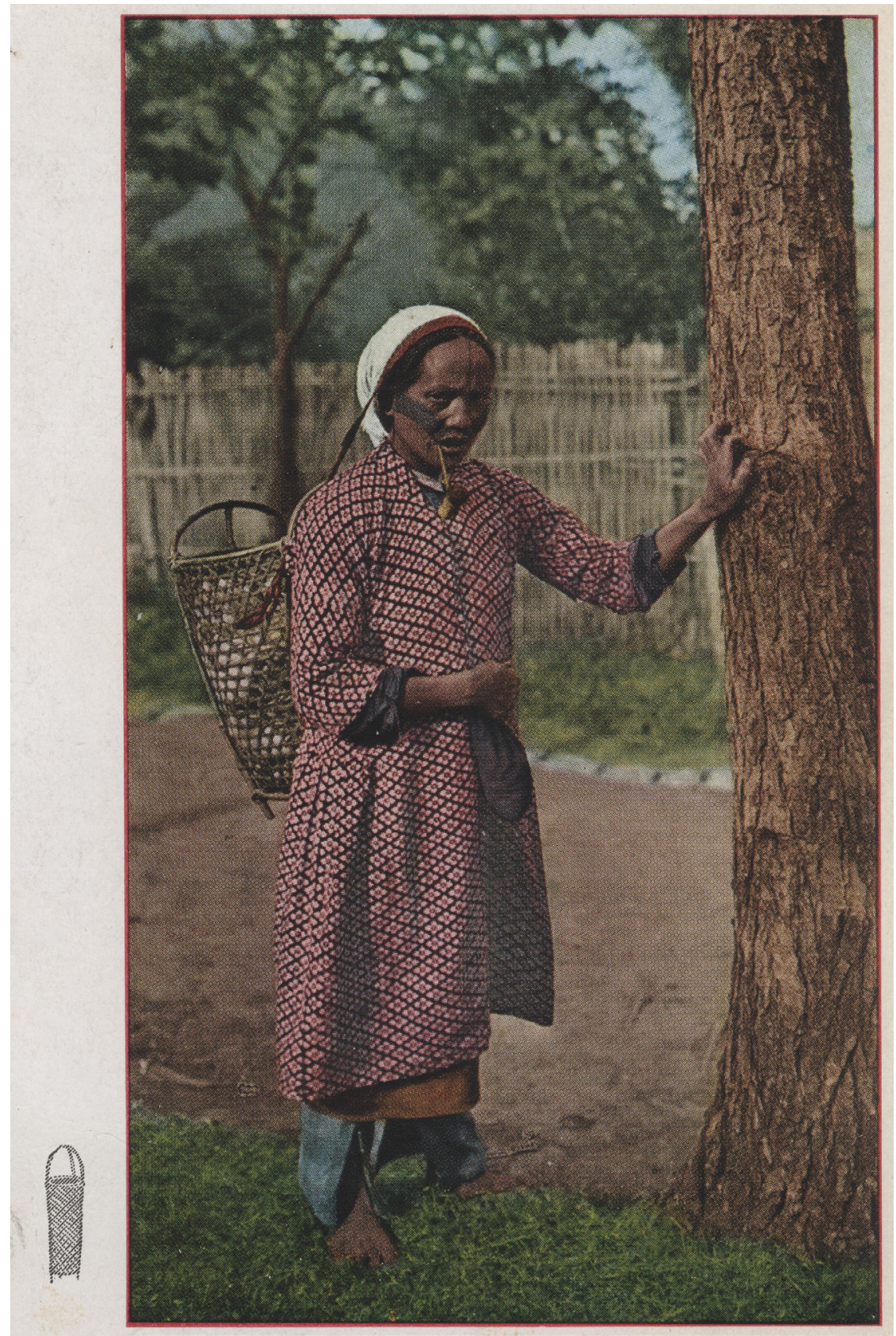

FIGURE 53. Jiaobanshan woman with basket and pipe, ca. 1930. KAPPAN-ZAN TAIWAN, wa306, East Asia Image Collection, Lafayette College, Easton, PA, accessed July 26, 2017, http:// digital.lafayette.edu/collections/eastasia/warner-postcards/wao3o6. 


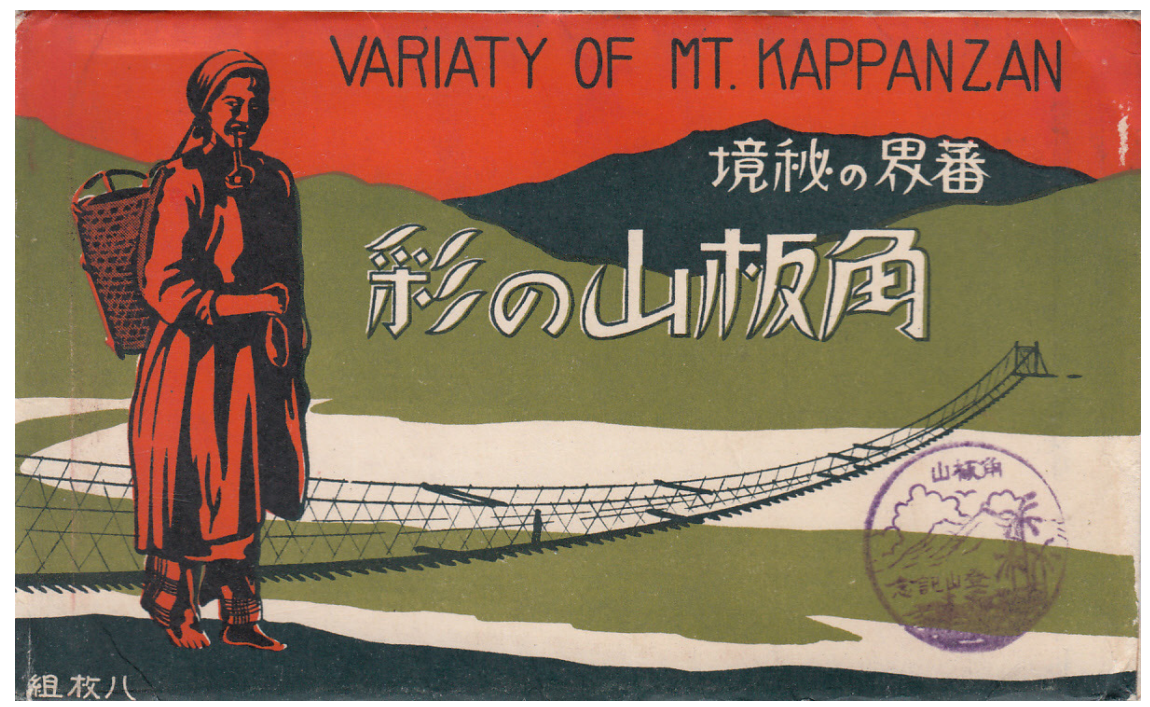

FIGURE 54. Postcard sleeve, “Jiaobanshan's hidden savage border," ca. 1930 (published by Taisho of Wakayama, Japan). [“The Savage Border's Unexplored Boundary: Mt. Kappanzan’s Variegated Coloration.”] This image is reproduced from an Internet auction.

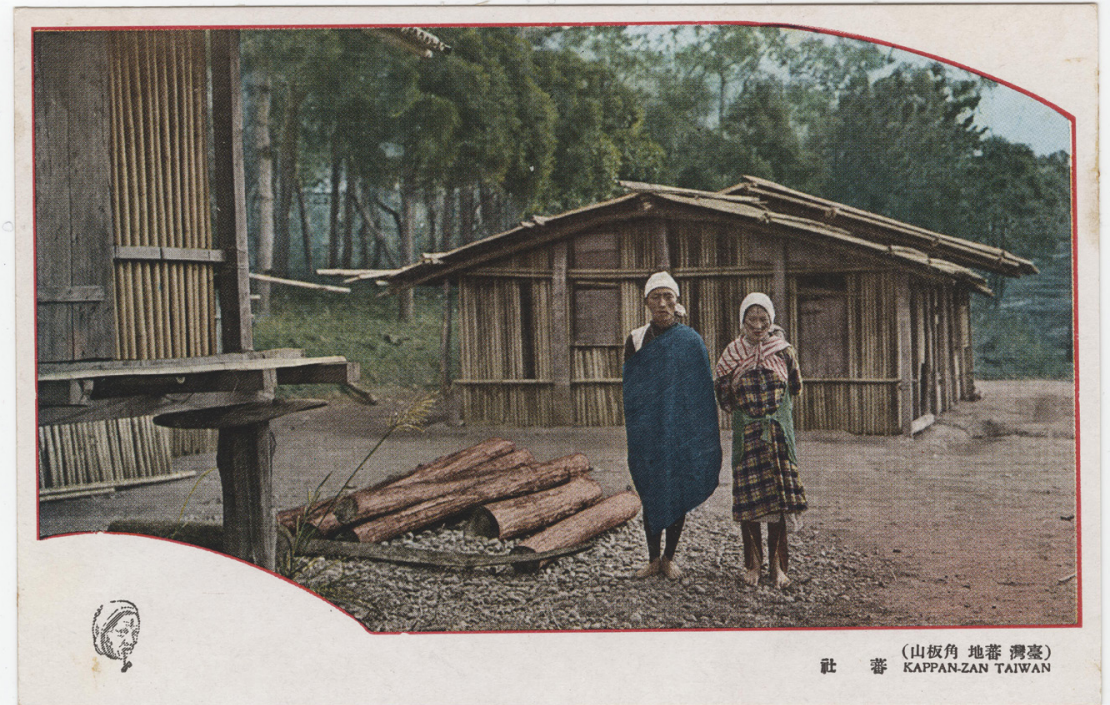

FIGURE 55. Couple in Jiaobanshan, ca. 1930. KAPPAN-ZAN TAIWAN, wao288, East Asia Image Collection, Lafayette College, Easton, PA, accessed July 26, 2017, http://digital.lafayette. edu/collections/eastasia/warner-postcards/wao288. 


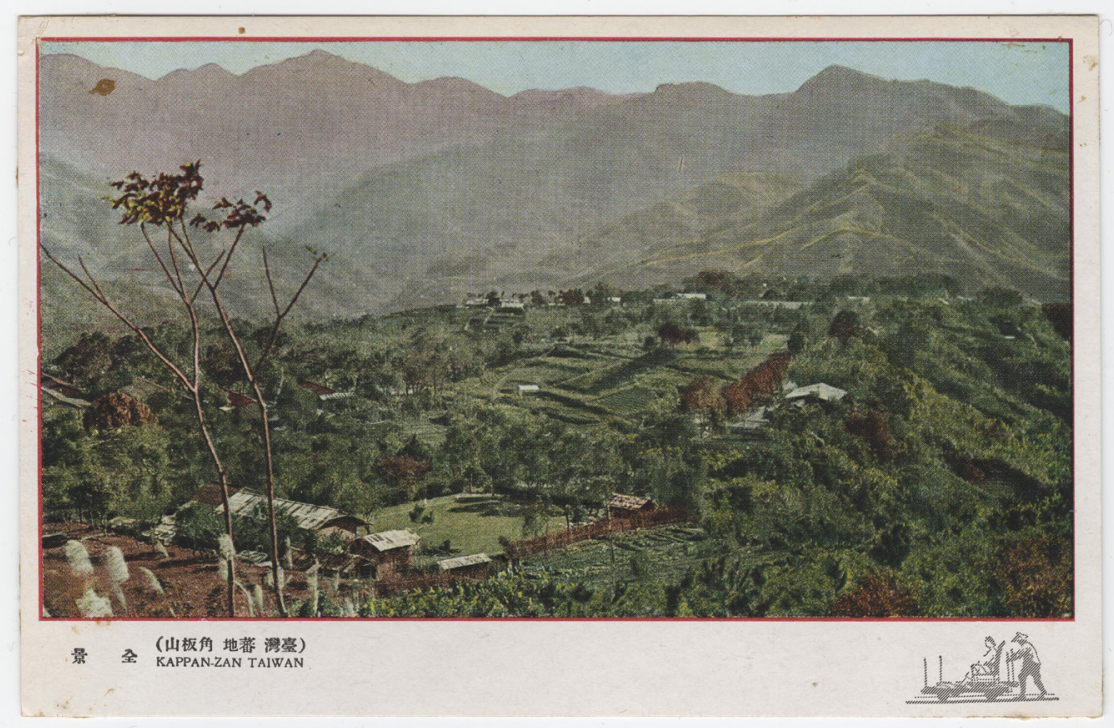

FIGURE 56. Mountains of Jiaobanshan, ca. 1930. KAPPAN-ZAN TAIWAN, wao291, East Asia Image Collection, Lafayette College, Easton, PA, accessed July 26, 2017, http://digital.lafayette. edu/collections/eastasia/warner-postcards/wao291.

Jiaobanshan worked as a show village, then, because it could provide the experience of "savage Taiwan" in such a way as to suggest that this "tame" settlement was indeed an exemplar of the rest of aborigine country. In this example, the deft use of imaginative geography, cropping, extrapolation, and logoization created a snapshot of Atayalness that was quickly apprehended and could be brought back or sent to Taipei, Gaoxiong, Tokyo, or Osaka in the form of a souvenir postcard set.

In 1935 the government-general hosted the Taiwan Hakurankai (Taiwan Expo) to celebrate its fortieth anniversary. One Taiwan Expo album held dozens of photographs that also appeared in the monthly bulletin Riban no tomo (Aborigine policemen's companion), published by the Keimukyoku Ribanka (Police Bureau, Aborigine Affairs Section) and in numerous postcard designs. These photographs were mostly shot by Segawa Kōkichi, an intimate of the Aborigine Affairs section chief Suzuki Hideo, and successor to Mori Ushinosuke as Japan's official portrait photographer of anthropological types. ${ }^{126}$ In the Atayal section of the album, the Jiaobanshan photo shows the "Japanizing" of Atayal models in "various kinds of antiquated and new-style clothing." Right below it is a photo of Atayal from the Wushe settlement of Paalan, the home of Iwan Robao, Kondō the Barbarian's first wife. The Paalan men and women show no outward signs of participation in the market for imported cloth or building materials (figure 57). 


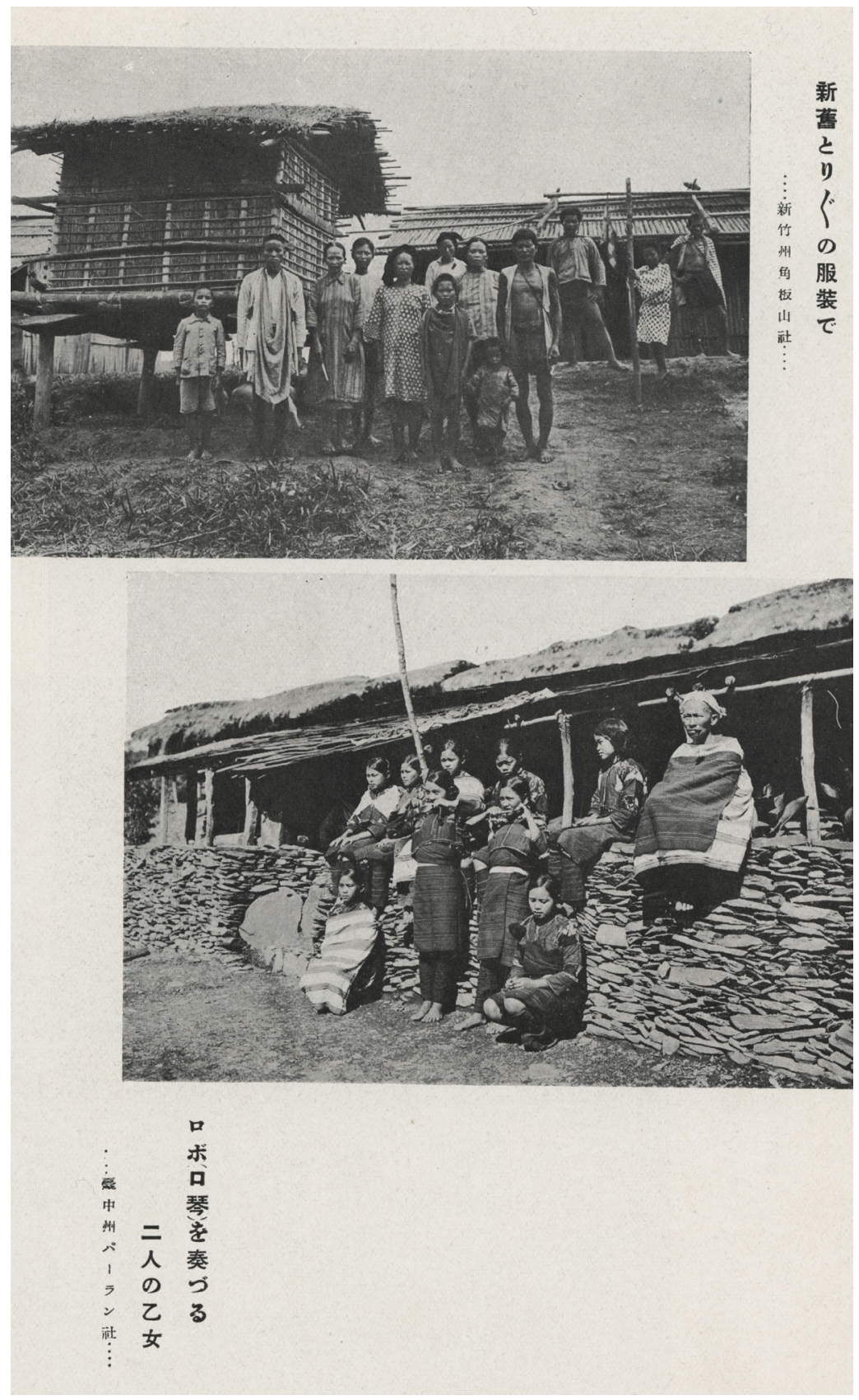

FIGURE 57. Contrasting photos of Jiaobanshan and Paalan, 1935. Top, "New and ancient various kinds of clothing: Xinzhu-shū Kappanzan-sha"; bottom, "Playing the mouth-harp: two maidens: Taizhong-shū Paalan-sha," from Suzuki Hideo, ed., Taiwan bankai tenbō (Taipei: Riban no tomo hakkōjo, 1935), 13. 


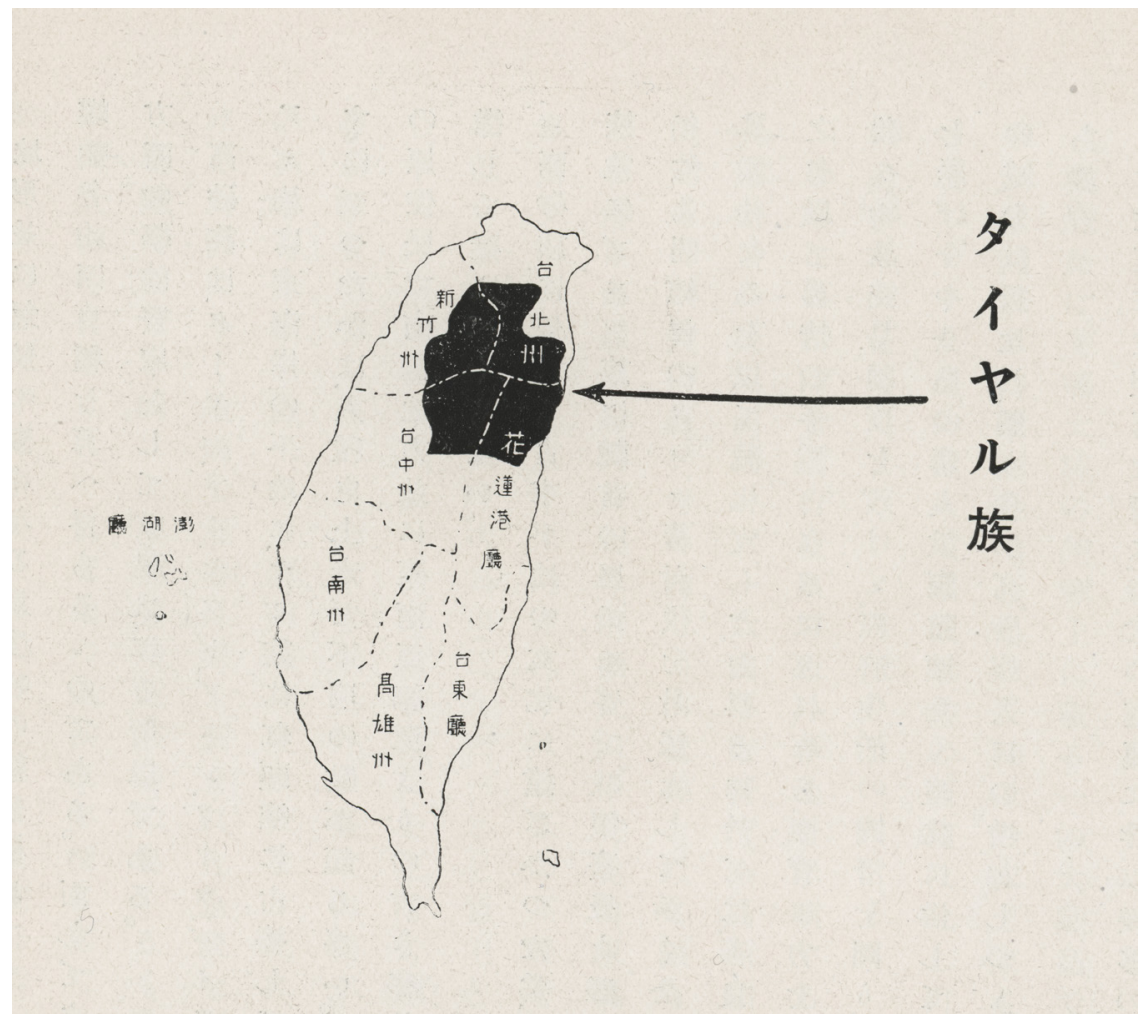

FIGURE 58. Second-order geobody of Atayal [“Taiyal tribe”]. Suzuki Hideo, ed., Taiwan bankai tenbō (Taipei: Riban no tomo hakkōjo, 1935), 6.

To suture these two photos together ideologically-the one displaying Japanization and the other what is being Japanized-the first page of the Atayal section of the souvenir book subsumes both images under the second-order geobody Atayal (figure 58). Because it was located in Atayal country and was configured horizontally within a common two-dimensional geobody, along with the visibly unassimilated inhabitants of Paalan, Jiaobanshan could represent the whole of untouched northern Taiwan, while exhibiting imperial progress toward Japanizing a wilderness that, a mere thirty years earlier, could only be represented as a borderland on the extremity of the Qing Empire. Here, in the dioramas, photographs, and ethnic maps of the 1935 exhibition, we find the fruition of the tandem operations of cartographic and racialist geobody construction. Whether strolling the fairgrounds, making a day trip to Wulai or Jiaobanshan to buy souvenirs, or perusing scholarly, commercial, or official photography of Taiwan Indigenous Peoples, Japanese people could quickly apprehend 1930s Atayal culture 


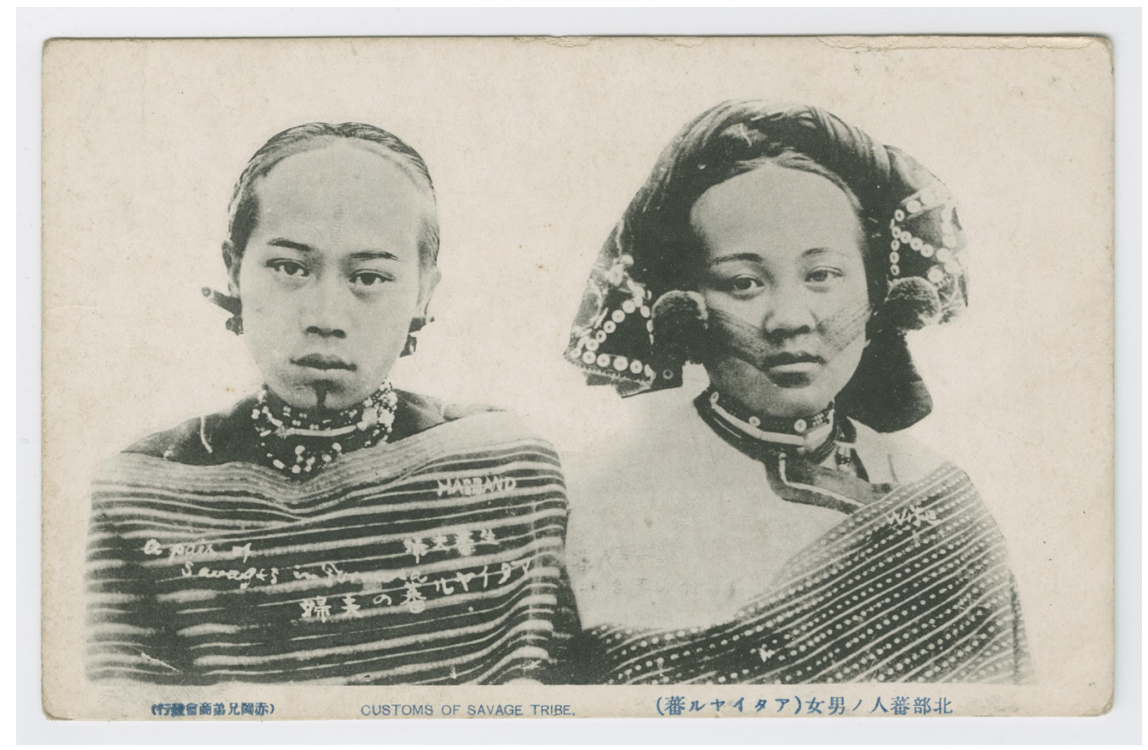

FIGURE 59. Marai and Yūgai of Rimogan, ca. 1903. Customs of Savage Tribe [sic], ip1471, East Asia Image Collection, Lafayette College, Easton, PA, accessed July 26, 2017, http://digital. lafayette.edu/collections/eastasia/imperial-postcards/ip1471.

and extrapolate it across the surface of Taiwan's interior. The ensemble of artifacts, maps, performances, images, and texts associated with Jiaobanshan represented Taiwan's aborigines at once as a population frozen in time and as a race that had been rescued from the neglect of the Qing dynasty by energetic Japanese officials.

For those who could not make the trip to an exhibition or a souvenir stand, government-published textbooks-compulsory reading for nearly the whole of Japan-employed the same stratagems. When the Ministry of Education finally revised its elementary-school geography texts in 1910 and 1919, it partially heeded Inō Kanori's criticisms by including portraits of Han Taiwanese. Each edition also updated its indigenous imagery, both relying on Mori's photographs from Wulai and Rimogan. The 1910 edition displayed profile mugshot etchings of Pazzeh of Wulai and Marai of Rimogan and captioned each as generic banjin (savages). The 1919 edition substituted Yūgai of Rimogan for Pazzeh of Wulai to present readers with a male and a female icon from the same settlement. Mori's June 1903 photograph (see figure 59) was the source of this illustration.

A couple of months before Mori photographed the Rimogan couple, he also took a scenic photograph of Atayal dwellings near Wulai (figure 60). This composition was reproduced in several government and commercial publications throughout the colonial period. The updated 1919 textbook rendered these photographs from 


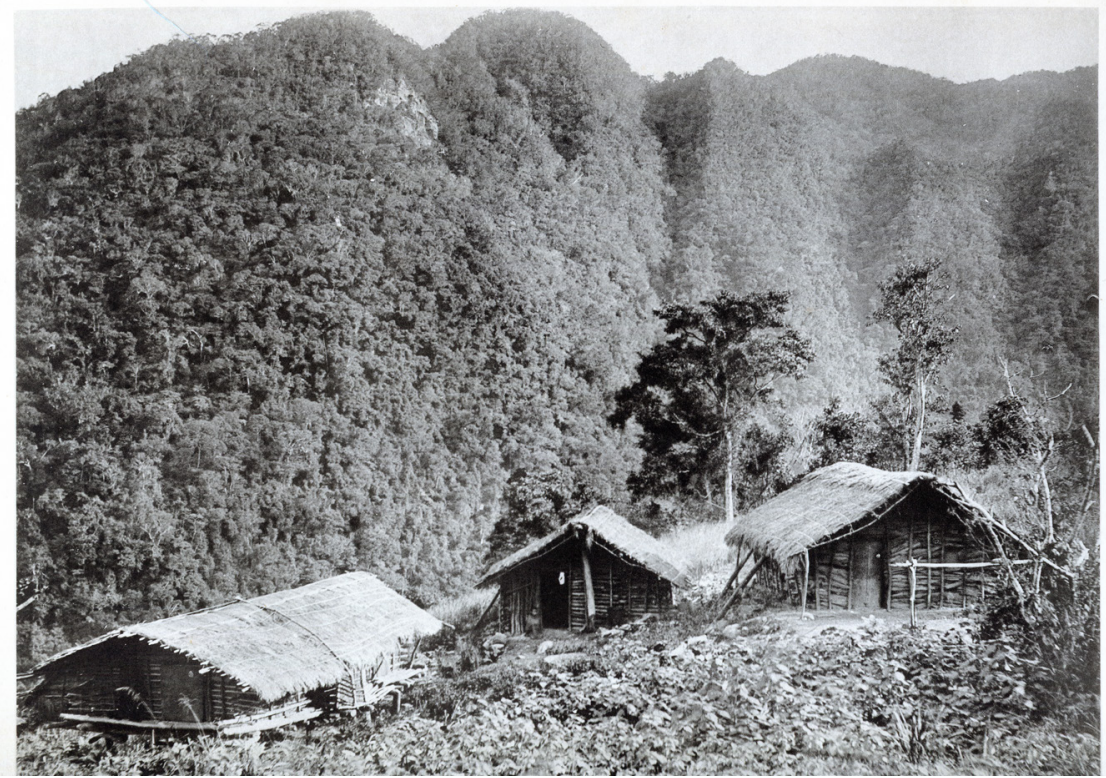

FIGURE 60. Wulai dwelling and granary, ca. 1903. Source: Mori Ushinosuke, ed., Taiwan banzoku zufu, vol. 1 (Taipei: Rinji Taiwan kyūkan chōsakai, 1915), plate 11.

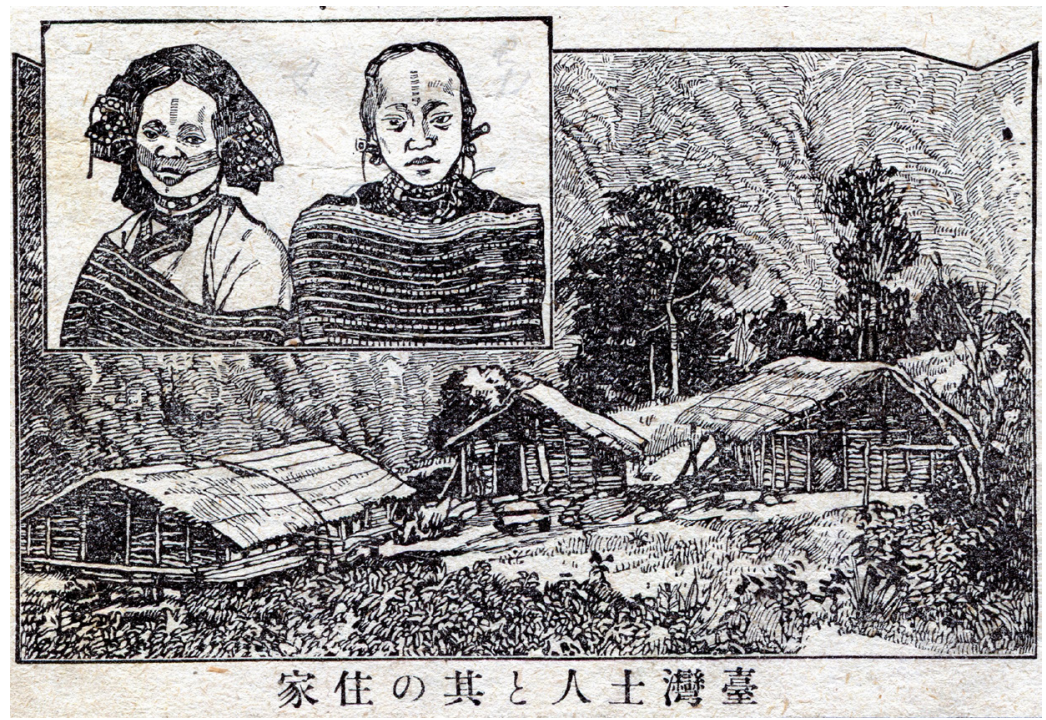

FIGURE 61. Yūgai and Marai, in textbook illustration, 1919. Monbushō, ed., Jinjō shōgaku chirisho kan ni (Tokyo: Monbushō, 1919), 16. 
distinct Atayal settlements into emblems of the same savage territory by inserting the Rimogan portrait of Yūgai and Marai into a Wulai setting (see figure 61). For the editors of the 1903, 1910, and 1919 geography textbooks, then, all indigenous people constituted a subpopulation. The 1919 version that merged Wulai and Rimogan imagery added a physical setting to cement the view that indigenes, no matter where they were photographed, were essentially hill people. ${ }^{127}$

\section{INDIGENOUS MODERNITY: A TWO-PART INVENTION}

A careful student of Taiwanese history and Japanese colonial rhetoric, upon attending the 1935 Taiwan Expo, might have asked why, after forty years of colonial rule, the indigenous people of Paalan (figure 58) were still dressing in handwoven fabrics, living in drafty slate houses, and working in pursuits far removed from the booming capitalist economy of the lowlands. After all, the Japanese state had managed to mobilize resources sufficient to win the Russo-Japanese War (1904-05), dislodge the Germans from Shandong in 1915, and overrun the three northeastern provinces of China in 1931. Why had it made such a poor showing in the uplands of Taiwan after four decades of opportunity?

The answer to this question brings us back to Foucault's formulation of the "disciplinary society." A number of scholars of Japanese colonial rule in Taiwan have observed that, in the lowlands where some 97 percent of Taiwanese lived, the Japanese colonial state was able to scale back its raw displays of punitive power by 1915 or so, with the crushing of the Ta-pa-ni rebellion. ${ }^{128}$ At the same time, the extension of the baojia system and the development of commercial law, public health and education, commoditization labor, and a system of safeguards for the protection of private property made great inroads into the warp and woof of daily life, in cities and in the countryside. This interlocking set of institutions and practices created a Taiwanese political economy that paid more to Tokyo in tax revenue than it cost to maintain in terms of expenditures taken from the national operating budget in Tokyo. A critical mass of lowland Han Taiwanese were, however grudgingly, bought into a disciplinary order. The incentive system that garnered this buy-in was itself expensive. To provide title deeds to land, access to commercial courts, irrigation projects, harbors, schools, hospitals, and other improvements, in such a way that they are in fact paid for by the colonized people themselves, required a "big bang" on the order of Gotō Shinpei's large spending spree of the early twentieth century. By the mid-1910s, the state-in varied degrees of alliance with Taiwanese capitalists, smallholders, professionals, policemen, officials, and baojia heads-had created a population that could not only produce surplus wealth but would also surrender enough of it to the government to pay for its own regulation. This form of society, wherein population increases redound to the power of the state (instead of to its detriment), is the desideratum of the disciplinary state. 
Yao Jen-to has concurred, asserting that the Japanese created a disciplinary society and biopolitical regime in Taiwan based on his interpretation of the state's profligate use of statistics and its vaunted interest in "forcing Taiwanese to be healthy." Curiously, Yao overlooks the fact that the first Japanese census left the indigenous territories completely blank and that much of Taiwan still fell outside the Government-General's tax base when Japan surrendered in $1945 .{ }^{129}$

The lands beyond the pale of Yao's analysis were at first defined as a zone of special administration, or the indigenous territories, because they were little known to Japanese administrators and did not appear on the ready-made grid inherited from the Qing. To rectify this situation, Sakuma Samata initiated his own "big bang" in the form of coordinated military offensives that culminated in the gokanen keikaku riban jigyō (five-year plan to control the aborigines). As we have seen, this scorched-earth approach succeeded to the extent that rebelling subjects were mostly disarmed. The mountain territories were, in fact, made safe for land and forest surveys. Abutting forests were cleared of toll states, and the obfuscating layer of tongshi (bicultural interpreters) that complicated relationships between primary producers and camphor capitalists was expelled from the savage border.

This is all to say that the post-Sakuma "aborigine district" was not a product of state neglect. After 1910 especially, and into the 1930s, the state proceeded to inventory, catalog, regulate, regiment, spatially array, and even nurture indigenous populations in order to extract wealth from the highlands. While this panoptical and surveillance-like activity bore superficial marks of discipline, it excluded the most important element: the state did not produce individuals in Taiwan's indigenous territories. Rather, it produced tribes, settlements, ethnic groups, and aborigines. Collective punishment, ad hoc justice, forced relocation, fixed prices at trading posts, poorly compensated corvée labor, and nonrecognition of ownership rights in forest lands were the lot of those who lived under special administration in colonial Taiwan. In these lands beyond the pale of the Han-dominated lowlands, the state did not invest in banks, courts, high schools, train stations, and other discipline-inducing infrastructure. In the specially administered areas, Taiwanese could not secure title deeds, compete for status in a public school system, open businesses in bustling port towns, or sell agricultural produce, hunted goods, or handicrafts at market prices.

Given the bounty of natural resources to be found in the highlands and the alacrity with which indigenes learned the Japanese language and new trades, it might seem puzzling that the state did not press its apparent advantage in 1915 to bring the highlands within the profitable zone of disciplinary society. The lower Hengchun Paiwan peoples, led by Pan Bunkiet and then his son, provide a telling example. These villages were of mixed Han, jukuban, and Paiwan residence. They were included in the regularly administered territory of Taiwan during the period Matsuoka Tadasu has characterized as one of temporary expediency. By 1906 almost all of the lower Hengchun Paiwan settlements were recognized as 
being sufficiently settled to pay taxes. Therefore, their territories would no longer be closed to immigrants, and they would fall under a structure of surveillance similar to neighboring baojia units. Thus, along with the Amis and the Puyuma of the eastern rift valley, the lower Hengchun Paiwan were, in many respects, integrated into the empire. Nonetheless, as culture bearers and denizens of ethnically defined subgeobodies, they occupied a liminal space: they were legally, economically, and administratively considered "civilized," but they were still accounted for in population counts as members of non-Han ethnic groups-as Paiwans. ${ }^{130}$ Moreover, they were still represented at tourist sites, in exhibitions, and in media as colorful examples of Taiwan's ethnic diversity. In a word, there was more to the permanent bifurcation of Taiwan into ethnically demarcated zones of difference than uneven capitalist development or relative levels of state neglect and oppression.

There are two major reasons for the arrested development of disciplinary society in colonial Taiwan. The first is negative. When TGG visionaries first mapped out schemes for ruling the island, Taiwan was Japan's only colony. As Japan added colonies (Karafuto and the Kwantung leased territory in 1905, Korea in 1910), the relative size and importance of Taiwan's uplands in the grand scheme of things shrank. Consequently, the cost of building a capitalist infrastructure that could produce a self-regulating disciplinary society in upland Taiwan was beyond the reach of the government-general by 1915 . As we saw in chapters 1 and 2, even when the empire was relatively flush after the Sino-Japanese War, savage-border policy was run on the cheap. Although Sakuma's five-year plan to control the aborigines was announced with great fanfare and a ¥15 million budget, the funds dried up before the work was finished, and Japan declared victory in 1914 out of exhaustion.

Nonetheless, from 1915 through 1925, a series of land and population surveys was conducted throughout the highlands. These projects set the stage for not only large forest giveaways but also forced migration movements and programs to transition indigenes into intensive agriculture. As Matsuoka Tadasu has argued, up until 1915, special administration was a temporary expedient-the original plan was to economically integrate the island economy. ${ }^{131}$ But despite the intrusions of irrigation projects, village relocation, and police government, the TGG policies kept the indigenous peoples intact as a separate population. Labor migration to the plains was discouraged; the fruits of intensive agriculture were not exported beyond the highlands but were consumed in the highlands themselves; and a majority of indigenes never paid taxes. Forced migration only occurred within the aborigine territory: peoples were not moved to areas under regular administration. Matsuoka documents a number of positions, including that of GovernorGeneral Den Kenjirō, that argued for the dissolution of the indigenous territory and Taiwan's administrative integration. Nonetheless, the government-general halted in its tracks at the old savage border, partly out of bureaucratic inertia but also because the Wushe uprising showed that indigenes were in need of 
different treatment. Moreover, argues Matsuoka, Japanese scholar-officials in the post-Wushe era tipped the balance in favor of preservationist policies. ${ }^{132}$

Matsuda Kyōko's analysis of Japanese policies, practices, and representational strategies in 1930s Taiwan confirms Matsuoka's hypothesis from a different vantage. Most importantly, Matsuda demonstrates that preservationism reached beyond the small circle of intellectuals discussed above and was translated into actual policy. This brand of preservationism, Matsuda argues, forced policemen, exhibition organizers, tourism operators, and administrators to walk a fine line. On the one hand, they needed to demonstrate the efficacy of Japanization programs and policies aimed at turning supposedly rootless, violent, wandering hunters into settled and peaceful agriculturalists. On the other hand, these same social engineers recoiled in horror at the prospect of indigenes becoming dandies who might participate in the consumer culture and urban cosmopolitanism that characterized Taipei in the 1930s. The reformed yet not modern indigenous Taiwanese would always be toilers on the soil, possessed of beautiful customs. They were an ethnically separate population requiring the ministrations of a trained corps of Japanese aborigine policemen-administrators to both ease them away from the worst of their old customs and shield them from the worst excesses of modernity.

The evidence for Matsuda's general claim is abundant. For one, whereas indigenous sightseeing programs in the late 189os through the 1910s brought small numbers of headmen and traditional leaders to urban Japan to scare them into submission by displaying Japanese military equipment and the advanced infrastructure of the home islands, tours in the 1930s involved large groups drawn from aborigine youth corps to demonstration farms within indigenous territory or to other flourishing agricultural sites in Taiwan or Japan. The goal was no longer to implant visions of Japan's overwhelming modernity and power but to educate indigenous people practically for crop production and stock breeding. ${ }^{133}$ Here we see an echo of the representational complex exhibited in the ethnic maps and photographs from the 1935 Taiwan Expo: progress was being made among the indigenes, but they remained and would always remain a rural folk rooted to the land and engaged in useful pursuits, as members of cohesive, traditionbound collectivities. Insofar as such a construction was a projection of Japanese conservative fantasies about the timeless virtues embodied in the imperiled and deracinated rural population of the home islands, it makes sense to view the indigenization of Taiwan's interior as a concomitant of Japanese nation building. ${ }^{134}$

More importantly, Taiwan-based academic, commercial, and official institutions had financial, emotional, and careerist stakes in the maintenance of the second-order geobody of the indigenous territory and its subdivision into ethnically defined language groups. Perhaps most prominent among them were the indigenous territory police and the aborigine youth corps that rose to prominence in the wake of the Wushe uprising. Both institutions were invested in the kind 
of modified preservationism described by Matsuda and had grown elaborate and cross-cutting organizational structures by the 1930s. The new youth leaders were fluent in Japanese, not Chinese. The lingua franca that linked them to other indigenous youth leaders separated them from Han Taiwanese, as it promoted sociability and identification with their indigenous police counterparts.

The interests of the indigenous police bureaucracy dovetailed with local boosters who lobbied for the selection of Taroko and Alishan National Parks above other sites in Taiwan. This group included primitivists like Lan Yinding and Ōzaki Hotsuma, Japanese alpinists, ethnologists at Taihoku Imperial University, musicologist Kurosawa Takatomo, and the many Japanese tourists, consumers, and collectors who were emotionally invested in the continued existence of Taiwan Indigenous Peoples as an identifiably separate and autochthonous population. ${ }^{135}$

To summarize, this book has considered the emergence of indigenous modernity as a two-part invention. The first part is a combination of military force sufficient to rob peoples in dynastic-state peripheries of their autonomy, coupled with an insufficiency of state resources to create disciplinary societies. In areas of Taiwan not already softened up by Chinese immigration and Qing governance, punishment remained ascendant over discipline into the 1930s. Here, it is important to consider the fact that the GMD itself, with many more resources, maintained the ethnically bifurcated form of rule in Taiwan. Its historical resilience indicates that "specially administered territory" is more than a residual category. Rather, these homelands embody positivities that gained considerable historical inertia during a moment in world-historical time marked by the ascendance of cultural pluralism.

These positivities sank roots in Taiwan coterminously with the so-called "cultural policy" in Korea, in tandem with a more diffuse, Wilsonian world order that moved sovereignty from an achieved status (civilized nations only) toward an ascribed status (all nations are ipso facto sovereign). The second part of this invention is then the construction of the second-order geobodies that formed the bulwarks of cultural pluralism in colonized Taiwan. As we have seen, the artistic, commercial, and scholarly impulses to collect, preserve, and idealize elements of indigenous cultures produced reified versions of them in museum collections, postcards, folklore anthologies, and ethnographic portraits. These preserved versions of indigenous culture have been sources of contestation, while they have also been utilized as resources for indigenous survival. The extent to which certain taxonomies, ethnonyms, or other articulations of indigenous culture are Japanese inventions is debatable. However, the shape and fundamental nature of the second-order geobody is not. It was under Japanese colonial rule that polygons such as the one illustrated in figure 58 were consolidated.

Over the course of its rule, the Taiwan Government-General zoned most of Atayal country as public land, save for a small percentage reserved for villages and their residents. This process amounted to land confiscation. Ownership of 
public lands was transferred to the GMD after retrocession in 1945. While the lands that were taken away from indigenes during the camphor wars and subsequent dispossession operations from 1898 through the 1930s were inhabited by myriad settlements and distinct collectivities then known as Gaogan, Dakekan, Nan'ao, or Tgdaya peoples, litigation with Taiwan's central government now aims to recover an Atayal homeland. In their analysis of the struggles surrounding the establishment of Maqaw National Park in north-central Taiwan, activist-scholars Yih-ren Lin, Lahuy Icyeh, and Da-Wei Kuan have argued that its proposed boundaries fall squarely within "Atayal people's traditional territory." The map they use to make this argument depicts Maqaw National Park enveloped by a much larger Atayal homeland. The space demarcated as territory to be restored to Atayal management, if not sovereignty, is not the home of a particular dialect community, ritual group, or voting district but rather is none other than the one drawn up by Japanese ethnologists, as shown in figures $2,3,34,51$, and $58 .{ }^{136}$

There are many good practical, historical, and legal reasons to consider this land as Atayal and for the central government to comanage public lands with Atayal people. There is no other effective way to configure autonomy, sovereignty, and rights in land nowadays, except territorially. The architects of the Japanese colonial project in ethnic bifurcation, who were many and not exactly in cahoots, did not predetermine how these thorny problems will be resolved. But this study suggests that they set the terms of engagement. 
